\title{
Stock characteristics, investor type and market myopia
}

Cristina Del Rio

Rafael Santamaria

Public University of Navarre (SPAIN)

\begin{abstract}
This paper investigates the role of stock characteristics and investor type in market myopia. Using the Generalized Method of Moments (GMM) to control for endogeneity, we obtain evidence indicating that market myopia is greater among stocks that are relatively hard-to-value and hard-to-arbitrage, and find this conclusion to be robust to the choice of proxy for these characteristics. We also obtain a significantly negative relationship between institutional ownership and market myopia, due to the former acting as informed traders who exploit mispricing created by individual traders. It is important to note that the impact of their role becomes significant only when they have a sizeable share in firm ownership, as is the case of UK mutual funds and pension funds and Spanish banks.
\end{abstract}

KEYWORDS: Market myopia, hard-to-value stocks, institutional investors

JEL: G14, G10

\section{Acknowledgement:}

We would like to thank the editor and referee for their helpful comments. This paper has received financial support from the Spanish Ministry of Economy and Competitiveness (ECO2012-35946-C02-01). An earlier version of this paper was published as Working Paper n 625 Colección de Documentos de Trabajo de la Fundación de las Cajas de Ahorros (FUNCAS)"

Corresponding author: Rafael Santamaria. Dpto.Gestión de Empresas. Universidad Pública de Navarra. Campus Arrosadía s/n 31006 Pamplona. Navarra. Spain.

Telephone number: 34948 169389, Fax number: 34948 169404, e-mail: rafael@unavarra.es. 


\title{
Stock characteristics, investor type and market myopia
}

\begin{abstract}
This paper investigates the role of stock characteristics and investor type in market myopia. Using the Generalized Method of Moments (GMM) to control for endogeneity, we obtain evidence indicating that market myopia is greater among stocks that are relatively hard-to-value and hard-to-arbitrage, and find this conclusion to be robust to the choice of proxy for these characteristics. We also obtain a significantly negative relationship between institutional ownership and market myopia, due to the former acting as informed traders who exploit mispricing created by individual traders. It is important to note that the impact of their role becomes significant only when they have a sizeable share in firm ownership, as is the case of UK mutual funds and pension funds and Spanish banks.
\end{abstract}

KEYWORDS: Market myopia, hard-to-value stocks, institutional investors

JEL: G14, G10 


\section{Stock characteristics, investor type and market myopia}

\section{1. - Introduction}

Abarbanell and Bernard (2000) define myopic pricing as "overvaluing near-term earnings and undervaluing long-term earnings" (p.221), and obtain evidence of this phenomenon in the US market, while also acknowledging that this apparent overvaluation of near-term earnings is actually due to measurement error ${ }^{1}$. In a later work, Bushee (2001) establishes a link between market myopia and investor type, arguing that the effect could be the result of institutional investor preferences pressuring managers into a near-term focus. His results show that the share of ownership held by transient institutions (mutual funds, pension funds, etc.) is positively related to myopic trading behavior, while bank preferences show no significant association with mispricing. However, some authors, without specifically analyzing the issue of market myopia, have shown that institutional investors are sophisticated traders, and that their presence contributes to efficient asset pricing. In particular, Bartov, Radhakrishnan, and Krinsky (2000), Jiambalvo, Rajgopal, and Venkatachalam (2002) and Collins, Gong, and Hribar (2003), characterize institutional investors as sophisticated traders, emphasizing that their superior capacity to acquire and process information gives them an advantage over other types of traders. Kumar (2009) shows, furthermore, that sophisticated investor activity is higher among stocks where individual investors exhibit stronger behavioral biases. This enables us to justify an alternative hypothesis to that offered by Bushee (2001), namely, that the participation of institutional investors, far from increasing market myopia, will, in fact, reduce its impact. To study this question, we introduce a variable that measures the share of ownership held by institutional investors, in order to test whether their presence increases market myopia, as found by Bushee(2001) or reduces it, in accordance with our hypothesis.

In another line of research, some behavioral finance models (see, among others, Daniel, Hirshleifer and Subrahmanyam, 1998 and 2001 or Hirhsleifer, 2001) have shown that investors' behavioral biases are stronger among relatively hard-to-value stocks operating in informationally-sparse environments. Recently, Kumar (2009) shows empirically that individual investors exhibit stronger behavioral biases when stocks are more difficult to value and when market-level uncertainty is higher. The examination of these issues in relation to market myopia might therefore require us to bring in a new variable, relating to

\footnotetext{
${ }_{1}^{1}$ According to Eames (1995), the reason for the higher prevalence of myopic behavior in the US market in comparison with others, such as the Japanese or German markets, may be due to country-specific market, economic or cultural characteristics.
} 
stock characteristics, to test whether myopic trading will be more intense among stocks that are harder to value and difficult to arbitrage.

The paper of Abarbanell and Bernard (2000) does not account for stock characteristics, despite reasons to suspect that its effect might vary across stocks. The examination of these issues in relation to myopic trading could require us to bring in a new variable, relating to stock characteristics, given that myopic trading will be more intense among stocks that are harder to value and difficult to arbitrage.

In order to test our hypothesis, we analyze two countries, the UK and Spain, which are clearly differentiated in terms of their market-clearing mechanisms and stock characteristics. They also possess contrasting profiles in terms of the cultural dimensions coined by Hofstede (2001). These conditions allow us to analyze the robustness of the results for market myopia as a function of stock characteristics, regardless of price-setting mechanisms or cultural dimensions.

In addition, each of these countries forms part of a very different financial system, the UK belongs to the Anglo-Saxon system which is characterized by shareholder dispersion and a wider separation between ownership and control, while Spain forms part of the Continental system, which has a highly concentrated ownership structure. This difference may have major importance when it comes to testing the effect of investor type on market myopia. It is also important to note that each system is dominated by a different type of institutional investor. Thus, in Continental Europe, the majority of institutional investors are banks, whereas, in the Anglo-Saxon system, they are mainly mutual funds or pension funds (MF\&PP).This last difference will enable us to ascertain whether determinant factor in explaining market myopia, is the weight of the latter type of institutional investors, in line with Bushee (2001) or the sophisticated nature of the trading activity of institutional investors, in line with our alternative hypothesis. Finally, in a break from previous studies, we use panel data, which enables us to control for unobservable heterogeneity across firms and overcome potential endogeneity problem.

Against this intriguing background, this paper contributes to the literature in various ways. One is the novel introduction of the role of stock characteristics, particularly the difficulty of pricing or arbitrage, into the controversy surrounding the source of market myopia. Our findings show that myopic trading is most intense when stocks are hard to value and difficult to arbitrage (HVDA stocks). This reveals the key role played by stock characteristics in explaining market myopia. In this kind of stocks, regardless of general market characteristics, the presence of this bias generates a greater difference between market price and fair value. Robustness tests show this finding to be robust to the choice of proxies for these characteristics. 
We also perform a joint examination of stock characteristics with the potential role of investor type. Contrary to the results shown in Bushee (2001), but favorable to the hypothesis raised in this paper, we obtain that the institutional ownership level is significantly negatively related to the intensity of market myopia, because it represents the impact of informed traders exploiting the mispricing errors of individual investors. This enables us to show that sophisticated trading activity by institutional investors is what contributes to price efficiency. This is a more important factor than those related to the policy of incentives to specific types of institutional investor. It should be noted that the influence of institutional investors is significant only when they hold a sizeable share of the ownership. The share of ownership held by banks in the case of the UK, and MF\&PP in that of Spain, has no significant effect, probably because they account, respectively, for such a small percentage in each country in overall terms. These findings are all the more noteworthy because they emerge from an analysis involving two countries with different financial systems: one Anglo-Saxon, the other Continental, and each with a different mix of institutional investors. These countries also have different market-clearing mechanisms and stock characteristics, as well as relevant differences in cultural dimensions. The robustness of our results to all these differences enables their generalization to other countries which, like our test countries, the UK and Spain, have developed financial markets.

The remainder of the paper is organized as follows. Section 2 presents the theoretical framework and the working hypotheses; section 3 the database; section 4 the results; and, finally, section 5 summarizes the main conclusions.

\section{2. - Theoretical framework and working hypotheses}

The behavioral finance literature has shown that behavioral biases force the market price to diverge from its equilibrium. In this respect, it is important to emphasize that the magnitude of these biases is not independent of stock characteristics. Indeed, psychological research suggests that people are more likely to use heuristics and "rules of thumb" when faced with more complex problems (see Khaneman and Tversky, 1973, and Khaneman, 2003).

There are also several papers that stress the role of limited attention, whereby cognitively-overloaded investors pay attention to only a subset of publicly available information (see Hirshleifer and Teoh, 2003, Peng and Xiong, 2006) and experimental laboratory research claims that limited attention affects how (individual or institutional) investors interpret accounting data (see Libby, Blommfield and Nelson, 2002). In fact, there is evidence to show that limited attention contributes to post-earnings announcement drift 
and accrual anomaly (see Hirshleifer, Lim and Hong, 2010). In this vein, there is an ample literature on how constraints on information processing affect investor behavior, thus supporting the notion that market myopia could be a consequence of limited investor attention ${ }^{2}$.

Stock characteristics have the potential to change or accentuate investor behavioral biases. In the context of investment decisions, Daniel, Hirshleifer and Subrahmanyam (1998, 2001) and Hirhsleifer (2001) have shown that investors' behavioral biases are stronger among relatively hard-to-value stocks operating in informationally-sparse environments. More recently, Kumar (2009) has shown empirically that individual investors exhibit stronger behavioral biases, such as the disposition effect, overconfidence, familiarity, representativeness, and limited attention, when stocks are more difficult to value and when market-level uncertainty is higher. As a consequence, investors' biases, particularly limited attention in the case in hand, will have more impact on some kind of stocks, especially on HVDA stocks. This leads us to test for a higher level of market myopia in this type of stocks.

The term "difficulty of valuation and arbitrage" has a wide interpretation. Kumar (2009) refers to the concept of "valuation uncertainty". Jiang, Lee and Zhang (2005) use a similar concept, which they call "Information Uncertainty", identifying it with "value ambiguity" or "the degree to which a firm's value can be reasonably estimated by even the most knowledgeable investors at reasonable costs". The level of information uncertainty is positively correlated with a particular form of decision bias (investor overconfidence) that is also positively correlated with arbitrage costs. The idea of introducing pricing difficulty, which is closely connected with arbitrage limits, was also suggested by Baker and Wurgler (2006) as a way to show variation in the effect of investor sentiment on stock prices. These authors refer to these stocks as "securities whose valuations are highly subjective and difficult to arbitrage". These stocks are also associated with higher information acquisition costs and greater information risk (see Schleifer and Vishny 1997 or Barberis and Thaler, 2003).

Researchers use a variety of proxy variables to identify HVDA stocks, although some are common to all studies. Baker and Wurgler (2006), for example, include Size, BTM and Volatility among the proxies for these stock characteristics. Information asymmetry is higher in smaller firms, which are less likely to attract the attention of market analysts. Very low BTM ratios may also represent future growth options and thereby greater

\footnotetext{
2 Although limited attention could be a source of market myopia, there are other potential sources of this bias, such as overconfidence (which may often be a source of limited attention, Hirshleifer and Teoh, 2003), or the certainty effect, prospect theory and anchoring.
} 
complexity than found in traditional business environments ${ }^{3}$. Stock volatility can also act as a reasonable proxy for valuation uncertainty, given that higher volatility makes earnings forecasts less reliable, and, all else being equal, increases default risk. Finally, given the emphasis on the role of limited arbitrage, we include a stock liquidity variable. Lower liquidity means fewer arbitrage opportunities. It also delays the flow of information into stock prices, making pricing more difficult. The variable used to capture liquidity is Turnover.

In order to test for the presence of market myopia we use the same model as Abarbanell and Bernard (2000), which is an adaptation of Ohlson's (1995). Bushee (2001) also sets out from Abarbanell and Bernard's (2000) model to analyze the role of investor type in the myopia effect. In this model, the value of the firm $\left(\mathrm{P}_{\mathrm{t}}\right)$ can be obtained as:

$$
P_{t}=b_{t}+\sum_{s=1}^{\infty}(1+r)^{-s} E_{t}\left(x_{t+s}-r \cdot b_{t+s-1}\right)
$$

Where $b_{t}$ is the accounting book value and $\sum_{s=1}^{\infty}(1+r)^{-s} E_{t}\left(x_{t+s}-r \cdot b_{t+s-1}\right)$ is the expected present value of all future abnormal earnings, where abnormal earnings are defined as actual earnings $\left(\mathrm{x}_{\mathrm{t}}\right)$ minus "normal" earnings, which are defined as prior book value multiplied by a rate of return (r) equal to the cost of equity capital. Following Abarbanell and Bernard (2000), we obtain that:

$$
E_{t}\left(P_{t+T}-b_{t+T}\right)=\sum_{s=T+1}^{\infty}(1+r)^{-s} E_{t}\left(x_{t+s}-r \cdot b_{t+s-1}\right)
$$

Thus:

$$
P_{t}=b_{t}+\left[(1+r)^{-1} E_{t}\left(x_{t+1}-r \cdot b_{t}\right)\right]+\left[\sum_{s=2}^{T}(1+r)^{-s} E_{t}\left(x_{t+s}-r \cdot b_{t+s-1}\right)+(1+r)^{-T} E_{t}\left(P_{t+T}-b_{t+T}\right)\right]
$$

Abarbanell and Bernard (2000) and Bushee (2001) identify the term $\left[(1+r)^{-1} E_{t}\left(x_{t+1}-r \cdot b_{1}\right)\right]$ as a one-year "near-term" forecasting horizon and $\left[\sum_{s=2}^{T}(1+r)^{-s} E_{t}\left(x_{t+s}-r \cdot b_{t+s-1}\right)+(1+r)^{-T} E_{t}\left(P_{t+T}-b_{t+T}\right)\right]$ as a "long-term value component". For our purposes, we use $\mathrm{T}=2$.

The final model takes the following form:

$$
\begin{aligned}
& P_{i, t}=\alpha_{0}+\alpha_{1} b_{i, t}+\alpha_{2}\left[\left(1+r_{i}\right)^{-1} E_{t}\left(x_{i, t+1}-r \cdot b_{i, t}\right)\right]+ \\
& +\alpha_{3}\left[\sum_{s=2}^{T}\left(1+r_{i}\right)^{-s} E_{t}\left(x_{i, t+s}-r_{i} \cdot b_{i, t+s-1}\right)+\left(1+r_{i}\right)^{-T} E_{t}\left(P_{i, t+T}-b_{i, t+T}\right)\right]+u_{i, t}
\end{aligned}
$$

\footnotetext{
${ }^{3}$ We should point out that very low BTM can also be associated with firms that are hard to value due to a higher risk of
} financial distress. 
Note that all variables in the model are scaled by $\mathrm{P}_{\mathrm{t}-1}$.

The null hypothesis under the assumption of forecasting efficiency is written as follows:

$H_{0}^{1}: \alpha_{0,}=0$ and $\alpha_{1}=\alpha_{2}=\alpha_{3}=1$.

The alternative hypothesis is that myopic pricing results in the overestimation of nearterm earnings and the under-estimation of long-term earnings, as follows:

$H_{1}^{1}: \alpha_{2}>1$ and $\alpha_{3}<1$.

As mentioned earlier, the main innovation of this paper with respect to previous studies of market myopia is that we analyze the role of stock characteristics, specifically those relating to pricing and arbitrage difficulties. To test our hypothesis that stock characteristics is the key variable behind variations in market myopia, we create model (2) which is a variation of model (1) including a dummy $D_{C}^{*}$ defined by characteristics associated with HVDA stocks. Specifically, we identify $D_{C}^{*}$ with the variable $\mathrm{D}_{\text {втм }}(\mathrm{Dv}$; Ds or $\mathrm{D}_{\mathrm{TU}}$ ), which takes the value 1 if the BTM ratio (volatility, size, or turnover) is above the median for the sample stocks and 0 otherwise. As a measure of robustness ${ }^{4}$, we also identify Dc with the joint fulfilment of volatility and BTM (D We also consider the fulfilment of the volatility characteristic jointly with any single other additional characteristic ( $\left.\mathrm{D}_{\mathrm{V}+\mathrm{OTHER}}\right)$. Obviously, all other stock characteristics are transformed in order to align their interpretation with that of volatility (high volatility, small size, low btm and low turnover).

$$
\begin{aligned}
& P_{i, t}=\alpha_{0}+\alpha_{1} b_{i, t}+\left(\alpha_{2}+\alpha_{2, C}^{*} \cdot D_{i, C}^{*}\right)\left[\left(1+r_{i}\right)^{-1} E_{t}\left(x_{i, t+1}-r_{i} \cdot b_{i, t}\right)\right]+\left(\alpha_{3}+\right. \\
& \left.\alpha_{3, C}^{*} \cdot D_{i, C}^{*}\right)\left[\sum_{s=2}^{T}\left(1+r_{i}\right)^{-s} E_{t}\left(x_{i, t+s}-r_{i} \cdot b_{i, t+s-1}\right)+\left(1+r_{i}\right)^{-T} E_{t}\left(P_{i, t+T}-b_{i, t+T}\right)\right]+u_{i, t}
\end{aligned}
$$

The null hypothesis that these stock characteristics have no significant influence in market myopia is written as:

$$
H_{0}^{2}: \alpha_{2, C}^{*}=0 \text { and } \alpha_{3, C}^{*}=0
$$

Our alternative hypothesis associating HVDA stocks with a higher level of market myopia is written as:

$$
H_{1}^{2}: \alpha_{2, C}^{*}>0 \text { and } \alpha_{3, C}^{*} \leq 0
$$

\footnotetext{
${ }^{4}$ In line with Corredor et al (2013a), we have incorporated an additional estimation in which HVDA stocks are required to qualify for inclusion in the fifth volatility quintile while meeting one other condition (high volatility and small size, high volatility and high growth options or high volatility and low turnover)
} 
These tests are performed for each of the above-mentioned stock characteristics (BTM, volatility, size and turnover). Thus, the alternative hypothesis, applied to each one individually, reads as follows:

$$
\begin{aligned}
& H_{1}^{2, B T M}: \alpha_{2, B T M}^{*}<0 \text { and } \alpha_{3, B T M}^{*} \geq 0 ; H_{1}^{2, V}: \alpha_{2, V}^{*}>0 \text { and } \alpha_{3, V}^{*} \leq 0 ; H_{1}^{2, S}: \alpha_{2, S}^{*}<0 \text { and } \alpha_{3, S}^{*} \geq 0 ; \\
& H_{1}^{2, T U}: \alpha_{2, T U}^{*}<0 \text { and } \alpha_{3, T U}^{*} \geq 0
\end{aligned}
$$

given that high volatility levels (low BTM, size and turnover levels) imply that pricing or arbitrage difficulties are more significant. Variables relating to more than one stock characteristic, D vbtm, D vsize, Dvtu or $\mathrm{D}_{\mathrm{V}+\mathrm{OTher}}$, are formally expressed in the same terms as volatility $\mathrm{D}_{\mathrm{v}}$.

Another issue relevant to the analysis of market myopia is the role of the type of investor in this effect. Although Bushee (2001) assumes institutional investors are sophisticated investors, he also states that some institutions face competitive pressures for strong shortterm performance and/or stringent fiduciary responsibilities that may foster an excessively short-term focus. According to this assumption, he finds that the level of ownership by "transient" institutions (institutions with short investment horizons) is positively related to the amount of firm value in expected near-term earnings. He also finds no significant evidence of mispricing when banks have high levels of ownership. As a consequence, his results suggest that institutions' short-term preferences translate into mispricing only when they use short investment horizons.

However, some authors, without specifically focusing on the question of market myopia, have shown that institutional investors are sophisticated traders, and that their presence contributes to efficient asset pricing. In particular, Bartov, Radhakrishnan, and Krinsky $(2000)^{5}$, Jiambalvo, Rajgopal, and Venkatachalam (2002) and Collins, Gong, and Hribar (2003), characterize institutional investors as sophisticated traders, emphasizing that their superior capacity to acquire and process information gives them an advantage over other types of traders. More specifically, Jiambalvo, Rajgopal, and Venkatachalam (2002) argue that sophisticated traders should be more skilled at using current information to forecast future earnings, and therefore, the higher the volume of stock traded by institutional investors, as proxied by higher institutional ownership, the better current prices will predict future earnings.

Furthermore, if market myopia is related to limited investor attention, which affects both naïve and professional investors (Libby, Blomfield and Nelson, 2002), institutional investors should be more attentive to accounting information. In fact, the accrual anomaly is stronger among stocks with lower institutional ownership (Collins, Gong and Hribar,

${ }^{5}$ Collins, Gong, and Hribar (2003) and Bartov, Radhakrishnan, and Krinsky (2000) tried to determine to what extent the degree of institutional ownership contributes to the removal of anomalies. 
2003). In this line, it is important to emphasize that the limited attention argument requires the additional assumption of unsophisticated investors in order to account for price and volatility patterns (Hong and Stein, 2007). Also, as mentioned earlier, Kumar (2009) shows that individual investors exhibit stronger behavioral biases when stocks are harder to value and market-level uncertainty is higher. He also finds, however, that informed trading activity, aimed at exploiting such biases, is higher among these stocks.

Thus, contrary to the findings of Bushee (2001), our hypothesis asserts that the higher the share of institutional investors in the ownership of the company, the smaller its level of market myopia. This hypothesis attaches more importance to the degree of sophisticated trading than to the policy of incentives of institutional investors.

To test the role of investor-type (individual investors versus institutional investors) in market myopia, we create model (3) which is a variation of model (1) including a dummy $D_{I}^{*}$ to capture one of the two institutional ownership measures in each case. Thus, model (3) takes the following form:

$$
\begin{aligned}
& P_{i, t}=\alpha_{0}+\alpha_{1} b_{i, t}+\left(\alpha_{2}+\alpha_{2, I}^{*} \cdot D_{i, I}^{*}\right)\left[\left(1+r_{i}\right)^{-1} E_{t}\left(x_{i, t+1}-r_{i} \cdot b_{i, t}\right)\right]+\left(\alpha_{3}+\right. \\
& \alpha_{3, I}^{*} \cdot D_{i, I}^{*}\left[\sum_{s=2}^{T}\left(1+r_{i}\right)^{-s} E_{t}\left(x_{i, t+s}-r_{i} \cdot b_{i, t+s-1}\right)+\left(1+r_{i}\right)^{-T} E_{t}\left(P_{i, t+T}-b_{i, t+T}\right)\right]+u_{i, t}
\end{aligned}
$$

Initially, variable $D_{I}^{*}$ is identified with the dummy $D_{\text {II }}$, which takes the value 1 if the firm has institutional investors among its shareholders and 0 otherwise. We then replace $\mathrm{D}_{\text {II }}$ with the variable $\mathrm{D}_{\text {IIM, }}$ which takes the value 1 if the proportion of firm ownership held by institutional investors is above the median of all firms in our data set and 0 otherwise

The null hypothesis that investor type has no explanatory power to explain market myopia takes the following form:

$$
H_{0}^{3}: \alpha_{2, I}^{*}=0 \text { and } \alpha_{3, I}^{*}=0
$$

Bushee's (2001) alternative hypothesis $H_{1}^{3, A}$, which claims the preference of institutional investors for near-term earnings, particularly MF\&PP, to be the underlying factor of myopic pricing, will take the form ${ }^{6}$ :

$$
H_{1}^{3, A}: \alpha_{2, I}^{*}>0 \text { and } \alpha_{3, I}^{*} \leq 0
$$

Our alternative hypothesis $H_{1}^{3, B}$ is based on the assumption that institutional investors are sophisticated and relatively better-informed traders. Thus, as their share in firm

\footnotetext{
${ }^{6}$ The reason we did not impose the restriction of a negatively-signed coefficient for the long-term component is, as we shall see later, that the long-term earnings coefficient is not significantly different from zero, and therefore, if we were to impose a negatively-signed coefficient on the dummy variable, this might impose a negative sign on the overall coefficient $\left(\alpha_{3}+\alpha_{3, I}^{*}\right)$ , which would be hard to explain in economic terms.
} 
ownership increases, the myopia effect will diminish. This hypothesis takes the following form:

$$
H_{1}^{3, B}: \alpha_{2, I}^{*}<0 \text { and } \alpha_{3, I}^{*} \geq 0
$$

Both hypotheses will be tested for the dummy variable capturing whether there are institutional investors in the firm ownership structure ${ }^{7}$ (DII), and for the variable representing the case in which institutional investors hold an above-the-median share in firm ownership (DIIM).

We also test separately for banks and MF\&PP, due to differences in goals and incentive systems that might affect the relative importance they attach to long- and near-term information.

We perform this test by identifying the variable $D_{I}^{*}$ with the variable $\mathrm{D}_{\text {в }}\left(\mathrm{D}_{\mathrm{M} \& \mathrm{P}}\right)$ which takes the value 1 if the firm's ownership structure includes banks (MF\&PP) and 0 otherwise. We also examine the dummy variable $D_{\text {BM }}$ ( $D_{\text {M\&PM }}$ ) which takes the value 1 if the share of firm ownership held by banks (MF\&PP) is above the median for the sample and 0 otherwise.

Finally, we test the joint influence of both variables (stock characteristics and investor type) on market myopia, by including both dummies. The resulting model takes the following form:

$$
\begin{aligned}
& P_{i, t}=\alpha_{0}+\alpha_{1} b_{i, t}+\left(\alpha_{2}+\alpha_{2, I} \cdot D_{i, I}^{*}+\alpha_{2, C} \cdot D_{i, C}^{*}\right)\left[\left(1+r_{i}\right)^{-1} E_{t}\left(x_{i, t+1}-r_{i} \cdot b_{i, t}\right)\right]+\left(\alpha_{3}+\alpha_{3, I} \cdot D_{i, I}^{*}\right. \\
& \left.+\alpha_{3, C} \cdot D_{i, C}^{*}\right)\left[\sum_{\tau=2}^{T}\left(1+r_{i}\right)^{-\tau} E_{t}\left(x_{i, t+\tau}-r_{i} \cdot b_{i, t+\tau-1}\right)+\left(1+r_{i}\right)^{-T} E_{t}\left(P_{i, t+T}-b_{i, t+T}\right)\right]+u_{i, t}
\end{aligned}
$$

For the sake of homogeneity, the dummies for investor type are $\mathrm{D}_{\mathrm{IM}}, \mathrm{D}_{\mathrm{BM}}$ and $\mathrm{D}_{\text {M\&PM. }}$

The null hypothesis of no effect associated with investor type or stock characteristics takes the following form:

$$
H_{0}^{4}: \alpha_{2, I}^{*}=\alpha_{2, C}^{*}=0 \text { and } \alpha_{3, I}^{*}=\alpha_{3, C}^{*}=0
$$

This hypothesis is tested for all combinations of investor type and stock characteristics associated with pricing difficulty.

Our alternative hypothesis asserts that market myopia is greater in harder-to-value and difficult-to-arbitrage stocks and those where institutional investors hold a low share in firm ownership.

$$
H_{1}^{4, A}: \alpha_{2, C}^{*}>0 \text { and } \alpha_{2, I}^{*}<0 ; \alpha_{3, C}^{*} \leq 0 \text { and } \alpha_{3, I}^{*} \geq 0
$$

Here also, it is necessary to account for each separate stock characteristic. Thus, the hypotheses for $\alpha_{2, C}^{*}$ and $\alpha_{3, C}^{*}$ when applied to each individually, read as follows

\footnotetext{
${ }^{7}$ We assume a company to have no institutional investors if their percentage of direct shareholdings is less than $0.01 \%$.
} 
$H_{1}^{4, B T M}: \alpha_{2, B T M}^{*}<0 \quad$ and $\alpha_{3, B T M}^{*} \geq 0 ; \quad H_{1}^{4, V}: \alpha_{2, V}^{*}>0 \quad$ and $\quad \alpha_{3, V}^{*} \leq 0 ; H_{1}^{4, S}: \alpha_{2, S}^{*}<0 \quad$ and $\alpha_{3, S}^{*} \geq 0 ;$ $H_{1}^{4, T U}: \alpha_{2, T U}^{*}<0$ and $\alpha_{3, T U}^{*} \geq 0$

\section{3. - The database and methodology}

\subsection{Database}

Given that the aim of this paper is to analyze the role of stock characteristics and investor types in explaining market myopia, we focus on two countries (the UK and Spain) that contrast in both these respects. Firstly, the two markets are clearly differentiated in terms of their market-clearing mechanisms (a price-driven market, in the case of the $\mathrm{UK}^{8}$ and an order-driven market in that of Spain) and stock characteristics (size, book-to-market or liquidity). Secondly, the UK and Spain form part of two very different financial systems: the Anglo-Saxon and the Continental system, respectively. One of the main characteristics attributed to firms belonging to the continental system is a highly concentrated ownership structure, which promotes stability and commitment, although it reduces capital market liquidity. Another key feature is the presence of control groups, which means that managers are kept under strict control unless they belong to the power group. Most firms are under owner-management. Cross share holdings are another widespread feature. These characteristics make firms based on the Continental, or insider, model quite different from those based on the Anglo-Saxon model, which is characterized by shareholder dispersion and a wider separation between ownership and control. In terms of institutional investor type, the majority of institutional investors in Continental Europe are banks, which take an active part in firm management, whereas, in the Anglo-Saxon system, they are mostly mutual funds or pension funds. Finally, cultural dimensions have been found to play a major role in explaining the effect of investor behavior in market prices (see Schmeling, 2009 or Corredor, et 2013b). Among European countries with developed financial markets, the UK and Spain possess contrasting profiles in terms of the cultural dimensions coined by Hofstede (2001). The UK, in particular, scores lowest for Uncertainty Avoidance Index (UAI) and highest for Individualism (IDV), while Spain scores highest IAU, and lowest for IDV, The two countries also score very differently in the dimensions of Power Distance Index (PDI) and Masculinity (MAS).

Our study period runs from January, 2002 to December, 2007. The firms in question are non-financial firms listed on the London Stock Exchange (SETS) and Spanish continuous market (SIBE). The decision to use non-financial firms is linked to our research objective, which is to measure the effect of institutional investors in relation to market myopia, and,

\footnotetext{
${ }^{8}$ More specifically, SETS is the London Stock Exchange's premier electronic trading service: it is a hybrid system combining electronic order-driven trading with market maker liquidity provision.
} 
more specifically, to discriminate between institutional investor types: i.e., banks versus MF\&PP. Data stock characteristics and I/B/E/S database for book value and earnings forecasts are obtained from Thomson Financial's databases (Datastream I/B/E/S, Datastream Academic and Datastream Worldscope). The data on ownership structure are obtained from the AMADEUS database.

\subsection{Methodology}

Since firms are heterogeneous, some of characteristics influencing firm value can be difficult to measure (see Himmelberg, Hubbard, and Palia, 1999). We therefore use panel data methodology to estimate the models because it allows us to control for unobservable heterogeneity in our models by decomposing the error term of our models into three components: a firm specific effect $\left(\eta_{i}\right)$ capturing unobservable heterogeneity, a time-specific effect $\left(d_{t}\right)$ capturing the influence of macroeconomic variables and random disturbance $\left(v_{i, t}\right)$.

We estimate our models by using the Generalized Method of Moments (GMM) which is consistent under unobservable heterogeneity. According to Florackis and Ozkan (2009), endogeneity can arise when the dependent and independent variables are correlated with hard-to-measure variables, or when there is a possibility that the explanatory variables may be correlated with past and present errors. According to Chenhall and Moers (2007a), endogeneity, as defined econometrically, is bound to be present in any empirical analysis. The choice of the estimation method, in practice, is not straightforward because it depends on the degree of endogeneity (see Chenhall and Moers 2007a and b, Larcker and Rusticus, 2007 and Van Lent 2007 for an interesting debate about endogeneity and empirical accounting and finance research). In this paper we use GMM to control for endogeneity problems by using instrumental variables (IV). Since it is quite difficult to choose good contemporaneous instruments, we follow the suggestion by Arellano and Bond (1991) to use all the right-hand side variables in the model lagged twice or more as instruments. This strategy of obtaining additional instruments by using the orthogonality conditions that exist between lagged values of the right-hand side variables improves the efficiency of our estimations with respect to other GMM estimators.

To check for potential misspecification of the models, we used the Hansen/Sargan test. This is a test of the over-identifying restrictions under the null hypothesis of instrument validity. We also include the $A R(2)$ statistic, which tests for lack of second-order serial correlation in the first-difference residuals. However, this statistic is only defined if $\min \left(\mathrm{T}_{\mathrm{i}}\right) \geq 5$, where $\mathrm{T}_{\mathrm{i}}$ is the time series observations of the $\mathrm{i}^{\text {th }}$ unit, a restriction that some of 
the analyzed samples fail to satisfy ${ }^{9}$. In any event, both tests lead in all cases to the same conclusion.

We compute the two-step estimator because it is efficient and robust to any pattern of heteroskedasticity and cross-correlation ${ }^{10}$. We also use Windmeijer (2005) finite sample correction of standard errors in the two-step estimation, without which the standard errors tend to be severely downward biased.

\section{4. - Results}

\subsection{Descriptive statistics}

Table I presents the basic characteristics of the UK and Spanish samples, showing, first, the average number of firms included in each of our analyses. The initial sample was much bigger $^{11}$ but was reduced after the application of several constraints. One, as already mentioned, excluded all financial firms. Another restricted the sample to firms covered simultaneously by Datastream ${ }^{12}$, so as to provide data on stock characteristics, by AMADEUS for data on ownership structure, and the I/B/E/S database for book value and earnings forecasts to enable us to estimate the Abarbanell and Bernard (2000) model on which we test our hypotheses. Finally, we require at least three consecutive observations per firm between 2002 and 2007. As a consequence, the final average number of sample firms is 386 for the UK and 85 for Spain. The average coverage of firms in the final sample is 5.17 years for the UK and 4.38 years for Spain.

Table I also gives the percentage of sample firms where institutional investors hold a share in the ownership. These data are broken down by investor type ${ }^{13}$. They include the percentage of firms in which an institutional investor is the major shareholder. The percentage ownership held by the major shareholder, the percentage ownership held by shareholders with over 5\% direct holdings (blockholders), and the percentage ownership held by institutional blockholders.

As already mentioned, the ownership data were drawn from the AMADEUS database, which supplies current data ${ }^{14}$ on firm owners, including their names and percentage of direct shareholdings, if above $0.01 \%$. It also provides a detailed typology of private investors

\footnotetext{
${ }^{9}$ Given that our sample is restricted to firms with at least 3 consecutive observations, few of the samples analyzed are likely to comply and therefore the M2 statistic is probably not correctly computed.

10 All estimations performed using Xtabond2 (Roodman, 2006). For further details, see Roodman (2006) "An Introduction to "Difference" and "System" GMM in Stata".

11 The initial sample comprised 650 UK firms and 120 Spanish firms.

12 Various filters suggested by Ince and Porter (2006) were applied to avoid bias from the naïve use of Thomson Datastream data.

${ }^{13}$ In line with the objectives of the study, we present the institutional ownership structure in the UK and Spain divided into two categories: banks and mutual funds/pension funds.

14 AMADEUS is a pan-European commercial database containing historical-financial information. It also includes data on firm ownership structure, but only for the current year. Therefore, to construct the database for the entire sample period (2002-2007), we used the different editions of the AMADEUS database for each year of the sample period (2002-2007).
} 
(individual, family or industrial company) and institutional investors (banks, insurance company, pension fund, mutual fund, the State or others). This classification, with its corresponding subdivisions, enabled us to calculate the percentage of shares held by each group of investors. All analyses were based on April values throughout the study period.

The data shown in Table I provide a clear overview of the afore-mentioned differences between the Anglo-Saxon and Continental systems. It is easy to see that the number of firms with at least one institutional investor in their ownership structure is much higher in the UK than in Spain. 91.34\% of the UK firms have at least one institutional investor, versus $78.8 \%$ of the Spanish firms. Nevertheless, in Spain, the ownership share held by mutual funds and pension funds is nowhere near that of the UK. This is obvious both from the data showing the percentage of firms where at least one mutual fund/pension fund has a share in the ownership (52.81\% in Spain versus $75.2 \%$ in the UK), and from the data showing the percentage of firms in which the major shareholder is a mutual fund/pension fund (6.20\% versus $31.5 \%)$. This difference may play a key role with respect to the aims of this paper, given that institutional investors, while sharing the common characteristic of being informed traders, nevertheless differ considerably in their incentive policies and timing of objectives. This situation will enable us to test whether the key variable in this analysis of market myopia is the presence of institutional investors per se, in line with the findings of Bushee (2001), or sophisticated trading (a characteristic shared by both types of institutional investor), in line with our alternative hypothesis.

Meanwhile, differences also emerge between UK and Spanish firms relating to ownership concentration, both in terms of the share of the major shareholder, which is $13.16 \%$ in the UK sample and $32.88 \%$ in that of Spain, and in terms of the percentage of ownership held by shareholders with over 5\% direct holdings (blockholders), which is notably higher in Spain (62.72\%) than in the UK (32.72\%). It should be noted, however, that the high percentage of blockholders in Spain is not due to institutional investors, but rather to individual investors or the State, since institutional blockholders account for $20.08 \%$ of firm ownership in the UK, whereas in Spain they account for only $13.14 \%$.

Table II gives the ownership percentages by institutional investor type, both in overall terms, and for the two sub-groups: banks and mutual funds / pension plans. It also contains the results of a t-test for two independent samples and Levene's test of homogeneity of variance, which shows that, despite a significant difference in the overall share of ownership held by institutional investors, $(23.34 \%$ for the UK and $18.61 \%$ for Spain) differences in investor type play the main role. Thus, whereas bank ownership of Spanish firms stands at approximately $9.20 \%$, in UK firms it is little more than half that 
level (4.81\%). In the case of firm ownership by mutual funds and pension funds, the balance switches to $12.90 \%$ in the UK versus $6.28 \%$ in Spain.

Table II also presents some descriptive statistics for the proxies for HVDA stocks: namely ${ }^{15}$, book to market (BTM), turnover (TU), volatility (V) and Size (S). Size is proxied by market value. For BTM and Size, we impute the April values for every year $t$ from data drawn directly from Datastream using the last 12 month average (Aprilt... Mayt-1). Turnover for April in year $\mathrm{t}$ is also estimated from the last 12 month average (April t... Mayt. 1) of trading volume in month $\mathrm{j}$ over the number of shares outstanding in month $\mathrm{j}$. Finally, volatility for April in year $t$ is approximated by the standard deviation of monthly stock returns over a period of 5 years (Aprilt...Mayt-5). Analysis of these characteristics, as already noted, reveals significant differences between the two markets. Perhaps the main similarity lies in average market value ${ }^{16}$, which, despite being higher in the UK, does not differ significantly, unlike the values of the remaining characteristics.

Specifically, the Spanish market presents a lower BTM ratio, possibly indicating that it has a larger proportion of firms with growth opportunities than the UK market. The volatility variable, which is significantly higher for Spain, appears to confirm this impression. Finally, liquidity is higher in the UK market, as shown by an average turnover that is practically double that of Spain. This could also be related to the UK's lower ownership concentration, since the higher the share of ownership held by small investors, the more liquid the market.

\subsection{Myopia and stock characteristics}

Following Abarbanell and Bernard (2000), the analysis begins by testing the two markets for over-estimation of near-term earnings and under-estimation of long-term earnings, both of which have been identified as myopic pricing behavior. As already stated, this test follows from the regression below:

$$
\begin{aligned}
& P_{i, t}=\alpha_{0}+\alpha_{1} b_{i, t}+\alpha_{2}\left[\left(1+r_{i}\right)^{-1} E_{t}\left(x_{i, t+1}-r \cdot b_{i, t}\right)\right]+ \\
& +\alpha_{3}\left[\sum_{s=2}^{T}\left(1+r_{i}\right)^{-s} E_{t}\left(x_{i, t+s}-r_{i} \cdot b_{i, t+s-1}\right)+\left(1+r_{i}\right)^{-T} E_{t}\left(P_{i, t+T}-b_{i, t+T}\right)\right]+d_{t}+\eta_{i}+v_{i, t}
\end{aligned}
$$

Where the error term $u_{i, t}$ is decomposed into three components: a firm specific effect $\left(\eta_{i}\right)$, a time-specific effect $\left(d_{t}\right)$ and random disturbance $\left(v_{i, t}\right)$.

\footnotetext{
${ }_{15}$ Following Baker and Wurgler (2006) and Kumar (2009)

${ }^{16}$ In Euros in both cases. In pounds sterling, average market value of the UK sample shares over the period considered is $4,092.44$.
} 
In this regression, the parameter $r$, denoting the capital cost for each firm, was derived from the CAPM model ${ }^{17}$, and expected book values $\left(E_{t}\left(b_{t+\tau-1}\right)\right.$ and $\left.E_{t}\left(b_{t+T}\right)\right)$ and expected earnings $\left(E_{t}\left(x_{t+\tau}\right)\right)$ were drawn from the I/B/E/S database. Finally, expected future prices $\left(E_{t}\left(P_{t+T}\right)\right)$ were obtained using the procedure described in Liu and Thomas (2000).

The results presented in Table III show this effect clearly. In fact, under the null hypothesis of behavior consistent with the classical theory of market efficiency, the constant would be zero and the near- and long-term earnings coefficients, $\alpha_{2}$ and $\alpha_{3}$, would equal one. However, as the table shows, the near-term earnings coefficient in both markets is clearly greater than one, while the long-term earnings coefficient is not different from zero, which means we can reject the null and accept the alternative hypothesis of market myopia ${ }^{18}$. This result is consistent with the findings of various other authors in finance literature (see Eames, 1995 and Abarbanell and Bernard, 2000).

Having observed significant market myopia, the first issue we wish to examine is the role of stock characteristics in the market myopia effect. If, as argued by Kumar (2009), pricing bias is stronger in HVDA stocks, they will, predictably, also be more prone to the market myopia effect, thus contradicting the null hypothesis, $H_{0}^{2}: \alpha_{2, C}^{*}=0$ y $\alpha_{3, C}^{*}=0$ and supporting our alternative hypothesis, $H_{1}^{2}: \alpha_{2, C}^{*}>0$ and $\alpha_{3, C}^{*} \leq 0$. Size, BTM and Volatility are proxies for these stock characteristics (hard to value and hard to arbitrage). Finally, given the emphasis on the role of limited arbitrage, we include a stock liquidity variable.

Panel A in Table IV presents the results for the UK. As can be observed, the coefficients on the variables to capture valuation uncertainty are all significant, allowing us to reject the null hypothesis, $H_{0}^{2}$ in all cases. They also have the expected signs ${ }^{19}$, as predicted by the alternative hypothesis, $H_{1}^{2}$. Therefore, stocks with greater growth options, higher volatility, lower turnover and smaller size are associated with higher overestimation of near-term earnings. The impact on long-term earnings is largely negligible. Panel $\mathrm{B}$ in Table IV presents the results for Spain. The findings are fully consistent with and supportive of the alternative hypothesis, $H_{1}^{2}$. They generally support our hypothesis that hard-to-value and hard-to-arbitrage stocks have characteristics that are likely to lead to

\footnotetext{
17 The data used to approximate risk-free assets are available from EUROSTAR as part of the series: EMU convergence criterion series - Monthly data. For market indices, we used the benchmark indices included in Datastream, specifically, Ibex35 and FTS100. The expected risk premia were based on excess market returns over the risk-free rate computed over the past 10 years.

18 For the null hypothesis $H_{0}^{1}: \alpha_{0}=0$ and $\alpha_{1}=\alpha_{2}=\alpha_{3}=1$ we obtain $\chi^{2}(4)=126.06$ with $\mathrm{p}=0.00$ for the UK and $\chi^{2}(4)=73.35$ $\mathrm{p}=0.00$ for Spain. The results are fairly similar for $\mathrm{H}_{0}: \alpha_{2}=\alpha_{3}=1$. That is, $\chi^{2}(2)=130.97, \mathrm{p}=0.00$ and $\chi^{2}(2)=70.03 \mathrm{p}=0.00$ for the UK and Spain, respectively.

19 The only exception is size, which is significant only at the $12 \%$ level.
} 
greater mispricing by attracting more noise traders ${ }^{20}$, thus confirming that market price is a less reliable proxy for fair value in this kind of stocks.

Finally, Table V (Panel A for the UK and Panel B for Spain) presents the results using the variables required to meet at least two characteristics of HVDA stocks. These are denoted by the dummy variables Dvbtm, Dvsize, Dvtu and Dv+other. The results are very similar to those obtained with the single-criterion variables, (especially volatility) and leave our conclusions unaltered. Given that the requirement to meet more than one characteristic leads to a substantial reduction in the size of the subsample we wish to examine, we will continue by using single-criterion variables throughout the remainder of the paper.

\subsection{Myopia and investor type}

In this part of the analysis, we wish to examine whether investor type plays a significant role in the phenomenon, as reported by Bushee (2001). As noted in the previous section, the null hypothesis $H_{0}^{3}$ assumes no explanatory power associated with investor type in relation to market myopia. Nevertheless, Bushee's (2001) alternative hypothesis $H_{0}^{3, A}$ is that higher proportions of institutional investors in firm ownership will increase the level of market myopia, given their preference for near-term earnings. However, our alternative hypothesis, $H_{0}^{3, B}$, assumes that higher proportions of institutional investors in firm ownership will reduce the effect of market myopia on stock market prices.

We use two separate tests to clarify this issue. In the first, we aim to see whether the mere presence of institutional investors in the firm ownership structure, irrespective of the size of their holding, causes any significant variation in the effect of market myopia on stock prices. In the second, we test the impact of ownership share by sorting the sample firms according to whether their institutional ownership level is above or below the median.

The results, presented in Panels A and B in Table VI, show the effect of the presence or absence of institutional ownership for UK and Spanish firms, respectively. Panels A and B in Table VII show the effect of an above-median level of institutional ownership. As can be seen, the effect of the presence/absence of institutional ownership is significant in the UK market, at least for the $\alpha_{2, I}^{*}$ coefficient, since $\alpha_{3, I}^{*}$ is not significantly different from 0 , but not in the Spanish market (the joint null hypothesis cannot be rejected at conventional levels). However, the findings are clearer on the variable representing a level of institutional ownership above the sample median, because the $\alpha_{2, I}^{*}$ coefficient for both

\footnotetext{
20 The findings coincide with those obtained for the analysis of the share of institutional ownership, which was performed on three groups $(25 \%, 50 \%$ and $25 \%)$ based on the characteristics of the stocks under consideration. The results are available upon request.
} 
countries is clearly significant and negative (although $\alpha_{3, I}^{*}$ are not different from zero). These results indicate that the level of institutional ownership is negatively related to the level of market myopia, thus providing support for our alternative hypothesis $2, H_{0}^{3, B}$ that, despite differences in incentive systems, all institutional investors trade sophisticatedly on market mispricings ${ }^{21}$.

As already noted, several studies ${ }^{22}$ have demonstrated the importance of drawing a distinction between the different types of institutional investor, based on incentive structures and, probably, also the timing of objectives. Thus, Table VI shows the results of the analysis by investor type. Panels A and B in Table VI show the results for the variable capturing the presence or absence of institutional ownership by banks, or MF\&PP, respectively, and Panels A and B in Table VII for the variable capturing the case in which the share of ownership held by banks (MF\&PP) is above the sample median.

Interestingly, the results reveal that the impact of market myopia differs according to the type of institutional investor. Particularly, they show that the null hypothesis of lack of explanatory power associated with investor type is rejected for UK firms where MF\&PP hold a share in the ownership and for Spanish firms where banks hold a share. This finding, which supports our alternative hypothesis $H_{1}^{3, B}$, is confirmed by the dummy variable for the presence or absence of institutional ownership, but even more clearly confirmed by the dummy variable for an above-median level of institutional ownership. In both cases, the effect on the near-term component is appreciable, but there is no significant effect on the long-run component. It should be noted that, contrary to the reasoning put forward by Bushee (2001), the emphasis is on their role as sophisticated traders, rather than on possible differences relating to their respective incentive systems or timing of objectives. The share of ownership held by banks in the case of the UK, and MF\&PP in that of Spain, has no significant effect, probably because they account, respectively, for such a small overall percentage in each country. Specifically, the percentage of ownership held by banks in the UK system is $4.81 \%$. Exactly the same occurs in the Spanish case, where the share of ownership held by MF\&PP over the sample period considered is fairly low (6.28\%). This finding highlights the usefulness of the joint examination of different settings, which allows us to make observations that, in a single-country analysis, might have led us to different conclusions, depending on the country analyzed. It is not our intention to use

\footnotetext{
${ }^{21}$ An analysis (with similar findings) was also performed dividing the sample into three groups (25\%, 50\% and $\left.25 \%\right)$, in terms of the global percentage of institutional ownership and institutional investor type. Nevertheless, given that a subsequent joint analysis of institutional ownership and stock characteristics was performed, the main analysis is on groups above and below the median.

${ }^{22}$ Bushee (2001) for market myopia and Dennis and Strinckland (2002) and Covrig and Ng (2004) for the relationship with trading volume and investor type.
} 
these results as a basis for claiming that all institutional investors act in the same way. We merely wish to assert that, in relation to the issue that concerns us, the similarities in their behavior outweigh the potential differences, and institutional investors cause various analogous effects in both markets.

\subsection{Market myopia, stock characteristics and investor type}

In light of the results described above, the aim of the last part of the paper is to examine the two factors jointly, that is, investor type and stock characteristics, to determine whether they both have explanatory power in relation to market myopia.

Table VIII shows the results for the UK. As expected, the null hypothesis, $H_{0}^{4}$, that investor type and stock characteristics related to pricing difficulties lack power to explain market myopia, is rejected in all cases. Analysis of the results in terms of BTM ratios clearly shows this to be a key factor in explaining market myopia, such that stocks with higher growth opportunities show the strongest bias. Similar results are obtained when stock volatility is examined, thus emphasizing the importance of this characteristic. The results for size and turnover are less important, since they are clearly significant only in the joint regression including the dummy variable showing a higher share of banks.

In terms of investor type, the results show that higher levels of institutional ownership significantly reduce market myopia. Note, however, that, for the case of the UK, the reduction is found only for the most significant institutional investor types, that is, MF\&PP.

Table IX shows the results for the Spanish stock market, which confirm the null hypothesis in all cases. Again, BTM emerges as an important characteristic, while banks are the only type of institutional investor with a significant effect. Similar findings emerge from the stock volatility regression analysis, at least in the separate regressions by investor type. While still relevant, Size is less significant where banks hold large ownership blocks. Finally, turnover is significant only where the ownership share of MF\&PP is above the sample median.

In conclusion, the findings for the influence of stock characteristics are similar for both countries, indicating the importance of the role played by stock characteristics, especially those related to pricing and arbitrage difficulties, in explaining market myopia. In both countries, the effect is found to be especially significant in high growth and high volatility stocks. The role of size and turnover is appreciable, but not as strong. There is more evidence of market myopia in small firms, although the effect is stronger in the Spanish case. Turnover is significant only for the less relevant type of institutional investor (MF\&PP in Spain and banks in England). This means that market price is a less reliable 
proxy for fair value in hard-to-value or difficult-to-arbitrage stocks. This is particularly true in the case of small stocks with high growth options and high-volatility or low-liquidity stocks.

In relation to the role played by investor type in market myopia, our findings contradict those of Bushee (2001) but support our hypothesis based on the arguments of several authors who emphasize the role of institutional investors as sophisticated traders, whose activity contributes to efficient asset pricing (see, among others, Bartov, Radhakrishnan, and Krinsky, 2000, Jiambalvo, Rajgopal, and Venkatachalam, 2002 and Collins, Gong, and Hribar, 2003). These results confirm that the effect of institutional ownership is negatively related to market myopia and reinforce the argument that the activity of the predominant type of institutional investor in each country (MF\&PP in the UK and banks in Spain) significantly reduces the bias associated with the overestimation of near-term earnings. As noted earlier, the fact that we obtain equivalent findings for both countries suggests that the sophisticated trading that characterizes all types of institutional investors prevails over any of their contrasting features, such as differences in their incentive policies or timing of objectives. Thus, as the volume traded by institutional investors grows, market myopia decreases, and the quality of price as a sufficient statistic increase ${ }^{23}$.

\section{5. - Conclusions}

This paper examines the influence of investor type and stock characteristics related to the difficulty of pricing or arbitrage in the phenomenon of market myopia. In order to investigate this issue, we analyze two European markets with different characteristics, in terms of market-clearing mechanisms, stock characteristics and investor mix, the latter being of particular importance in the analysis of the role of institutional investors in the market myopia phenomenon.

Our results show that market myopia is greater in stocks that are hard to value and difficult to arbitrage. The strongest effects are observed in high growth options and highly volatile stocks. We find that turnover and, to a lesser extent, size also have a significant influence.

We also find that the type of investor driving the price-setting process plays a key role in the effect of market myopia on stock prices. Contrary to the results reported by Bushee (2001) for the US market, our findings show that the level of institutional ownership is negatively related to market myopia. It should be noted that the influence of institutional investors is significant only when they hold a sizeable share of the ownership, as in the case

\footnotetext{
${ }^{23}$ Our findings suggest that well-organized and liquid markets, which the FASB and IFRS assume to be a sufficient condition to make market price a valid proxy for fair value, is, in fact, a necessary, but not sufficient, condition for this assumption. We find at least two additional factors for consideration: namely, stock characteristics and investor type.
} 
of UK MF\&PP and Spanish banks. The joint regression including both variables produced practically identical findings, thus underlining the role of investor type and stock characteristics in market myopia.

These findings are all the more remarkable because they emerge from an analysis involving two countries that differ in various ways. One has an Anglo-Saxon financial system, the other Continental, and each has a different mix of institutional investors, different market-clearing mechanisms and stock characteristics, and relevant cultural differences. The robustness of our results to all these differences enables their generalization to other countries with developed financial markets.

Finally, the behavioral finance literature has already shown that mispricings are linked to issues such as the level of sentiment (see Baker and Wurgler, 2006). We believe that an interesting direction for further research would be to explore whether market myopia is related to the level of investor sentiment or to economic cycle issues.

\section{REFERENCES}

Abarbanell, J. and Bernard, V. (2000) Is the U.S. Stock Market Myopic?, Journal of Accounting Research, 38 (2), pp. 221-242.

Arellano, M. and Bond, S. (1991) Some tests of specification for panel data: Monte Carlo evidence and an application to employment equations, Review of Economics Studies, 58, pp. 227-297.

Baker, M. and Wurgler, J. (2006) Investor Sentiment and the Cross-Section of Stock Returns, Journal of Finance, 61(4), pp. 1645-1680.

Barberis, N. and Thaler, R. (2003) A Survey of Behavioral Finance, Handbook of the Economics of Finance, Chapter 18, edited by G. M. Constantinides, M. Harris, and R. Stulz. Elsevier/North-Holland.

Barth, M.E. and Landsman, W.R. (1995) Fundamental Issues Relating to Using Fair Value Accounting for Financial Reporting, Accounting Horizons, 9(4), pp 97-107.

Bartov, E., Radhakrishnan, S. and Krinsky, I. (2000) Investor Sophistication and Patterns in Stock Returns After Earnings Announcements. The Accounting Review 75, pp. 43-63.

Bushee, B.J. (2001) Do Institutional Investors Prefer Near-Term Earnings over Long-Run Value?, Contemporary Accounting Research, 18(2), pp. 207-46.

Covrig, V. and Ng, L. (2004) Volume autocorrelation, information, and investor trading, Journal of Banking and Finance, 28, pp. 2155-2174.

Collins, D.W., Gong, G. and Hribar, P. (2003) Investor Sophistication and the Mispricing of Accruals, Review of Accounting Studies, 8, pp. 251-276 
Corredor P., Ferrer E. and Santamaria R. (2013a) Value of Analysts' Consensus Recommendations and Investor Sentiment, Journal of Behavioral Finance, 14:3, 213-229

Corredor P., Ferrer E. and Santamaria R. (2013b) Investor sentiment effect in stock markets: Stock characteristics or country-specific factors? International Review of Economics and Finance 27 (2013) 572-591.

Chenhall R.H and Moers F. (2007a) The Issue of Endogeneity within Theory-Based, Quantitative Management Accounting Research, European Accounting Review, 16:1, pp.173-196

Chenhall R.H and Moers F. (2007b) Endogeneity: A Reply to Two Different Perspectives, European Accounting Review, 16(1), pp.217-221

Daniel, K., D. Hirshleifer; and A. Subrahmanyam. (1998) Investor Psychology and Security Market Under and Overreactions. Journal of Finance, 53,pp. 1839-1885.

Daniel, K., D. Hirshleifer and A. Subrahmanyam.(2001) Overconfidence, Arbitrage, and Equilibrium Asset Pricing. Journal of Finance, 56, pp. 921-965.

Dennis, P.J.; Strinckland, D. (2002). "Who Blinks in Volatile Markets, Individuals or Institutions?, Journal of Finance, 57 (5), pp. 1923-1949.

Eames, M.J. (1995) Institutional Investor Myopia, Ownership, Earnings, and Returns. UMI Dissertation Services.

Florackis, C. and Ozkan, A. (2009) The impact of managerial entrenchment on agency costs: evidence using UK panel data, European Financial Management, 15(3), pp. 497-528.

Himmelberg, Ch, R., Hubbard G., and Palia D. (1999). "Understanding the Determinants of Managerial Ownership and the Link Between Ownership and Performance."Journal of Financial Economics. 53, pp. 353-384.

Hirhsleifer, D. A. (2001) Investor Psychology and Asset Pricing, Journal of Finance, 56, pp. 1533-1597.

Hirhsleifer, D. (2003) and Teoh S.A.(2003) Limited attention, information disclosure, and financial reporting, Journal of Accounting and Economics,36, pp.337-386.

Hitz J.M. (2007) The Decision Usefulness of Fair Value Accounting- A theoretical Perspective. European Accounting Review, 16 (2), pp. 323-362.

Hofstede, G., (2001): “Culture’s consequences: comparing values, behaviors, institutions, and organizations across nations", Sage Publication, Beverly Hills.

Ince, O. and Porter R. (2006) Individual Equity Return Data from Thomson Datastream: Handle with Care! Journal of Financial Research, 29(4), pp. 463-479.

Jiang, G., Lee, Ch.M. and Zhang, Y. (2005) Information uncertainty and expected returns, Review of Accounting Studies, 10, pp. 185-221. 
Jiambalvo, J., Rajgopal, S. and Venkatachalam, M. (2002) Institutional ownership and the extent to which stock prices reflect future earnings, Contemporary Accounting Research, 19(1), pp. 117-45.

Kahneman, D. (2003) Maps of Bounded Rationality: Psychology for Behavioral Economics. American Economic Review, 93, pp. 1449-1475.

Kahneman, D., and Tversky, A. (1973) On the Psychology of Prediction.” Psychological Review, 80, pp. 237-251.

Kent, D., Hirshleifer, D. and Subrahmanyam, A. (1998) Investor Psychology and Security Market Under- and Overreactions, Journal of Finance, 53(6), pp 1839-1885.

Kumar, A. (2009) Hard-to-Value Stocks, Behavioral Biases, and Informed Trading, Journal of Financial and Quantitative Analysis, 44(6), pp. 1375-1401.

Larcker, D. F. and Rusticus, T. O. (2007) Endogeneity and empirical accounting research, European Accounting Review, 16(1), pp. 207-215.

Laux C. and Leuz C. (2009) The crisis of fair-value accounting: making sense in the recent debate, Accounting Organization and Society, 34, 826-834.

Liu, L. and Thomas, J. (2000) Stocks returns and accounting earnings. Journal of Accounting Research, 38(1), pp. 71-101.

Ohlson, J. (1995) Earnings, book values, and dividends in equity valuation. Contemporary Accounting Research, 11 (2), pp. 661-687.

Plantin G., Sapra H. and Shin S.H. (2008) Marking to market: panacea or pandora's box, Journal of Accounting Research, 46 (2), pp. 435-460.

Quagli A. and Avallone F. (2010) Fair value or cost model? Drivers of choice for IAS40 in the Real State Industry, European Accounting Review, 19 (3), pp.461-493.

Schmeling, M., (2009), Investor sentiment and stock returns: some international evidence, Journal of Empirical Finance, 16, pp. 394-408

Shleifer, A. and Vishny, R. W. (1997) The Limits of Arbitrage. Journal of Finance, 52, pp. $35-55$.

Van Lent L. (2007): Endogeneity in Management Accounting Research: A Comment, European Accounting Review, 16(1), 197-205

Windmeijer, F. (2005) A finite sample correction for the variance of linear efficient two-step GMM estimators, Journal of Econometrics, 126, pp. 25-51. 
Table I. Sample characteristics.

\begin{tabular}{lcc}
$\mathbf{2 0 0 2 - 2 0 0 7}$ & UK & Spain \\
\hline $\begin{array}{l}\text { Number of firms in sample } \\
\text { Number of firms where institutional investors hold }>=0.01 \% \text { share in the }\end{array}$ & 396 & 85 \\
ownership & $91.34 \%$ & $78.81 \%$ \\
Number of firms where Banks hold $>=0.01 \%$ in the ownership & $45.4 \%$ & $62.14 \%$ \\
Number of firms where Mutual Funds/Pension funds hold >=0.01\% share in & $75.2 \%$ & $52.81 \%$ \\
\hline the ownership & $57.17 \%$ & $23.64 \%$ \\
Number firms where the major shareholder is an Institutional Investor & $13.28 \%$ & $11.82 \%$ \\
Number firms where the major shareholder is a Bank & $31.5 \%$ & $6.20 \%$ \\
\hline Number firms where the major shareholder is a Mutual Fund/Pension Fund & $13.16 \%$ & $32.88 \%$ \\
\% Ownership held by the major shareholder & $32.76 \%$ & $62.72 \%$ \\
\% Ownership held by blockholders $>=5 \%$ & $20.08 \%$ & $13.14 \%$ \\
\hline
\end{tabular}

Percentage of sample firms where institutional investors hold a share in the ownership by investor type. Breakdown of institutional ownership structure in the UK and Spain into Banks and Mutual Funds and Pension Plans (MF\&PP). Percentage of firms in which an Institutional Investor/Bank/MF\&PP is the major shareholder. Percentage ownership held by the major shareholder. Percentage ownership held by shareholders with over 5\% direct holdings (blockholders), and the percentage ownership held by Institutional Blockholders. 
Table II. Descriptive statistics

\begin{tabular}{cccccccc}
\hline & \multicolumn{5}{c}{ \% Ownership } & \multicolumn{5}{c}{ Stock characteristics } \\
\hline & Inst.Investors & Banks & MF\&PP & BTM & Turnover & Volatility & Size \\
\hline Panel A:UK & & & & & & & \\
mean & 23.34 & 4.81 & 12.90 & 0.39 & 129.02 & 0.08 & $6,047.24$ \\
p50 & 19.21 & 3.01 & 8.16 & 0.35 & 113.12 & 0.07 & $1,631.32$ \\
\hline Panel B: SP & & & & & & & \\
mean & 18.61 & 9.20 & 6.28 & 0.46 & 67.16 & 0.10 & $4,763.25$ \\
p50 & 15.04 & 5.17 & 2.28 & 0.45 & 49.44 & 0.09 & $1,631.74$ \\
\hline t-statistic & 4.33 & -9.17 & 8.11 & -3.70 & 11.93 & -7.50 & 1.35 \\
p-value & 0.00 & 0.00 & 0.00 & 0.00 & 0.00 & 0.00 & 0.18 \\
Levene & 1.33 & 123.39 & 52.89 & 0.97 & 18.98 & 0.03 & 4.45 \\
p-value & 0.25 & 0.00 & 0.00 & 0.32 & 0.00 & 0.87 & 0.03 \\
\hline
\end{tabular}

Descriptive statistics for percentage ownership held by institutional investors and for the proxies for hard-to-value and/or hard-to-arbitrage stocks for the period 2002-2007. The ownership percentage is shown by institutional investor type, both in overall terms (Institutional Investors), and for the two sub-groups: Banks and Mutual Funds and Pension Plans (MF\&PP). For book to market ratio (BTM) and Size (Market Value), we impute the April values for every year $\mathrm{t}$ from data drawn directly from Datastream using the last 12 month average (April t... May t.1). Turnover for April in year $\mathrm{t}$ is also estimated from the last 12 month average (April t... May t-1) of trading volume in month $\mathrm{j}$ over the number of shares outstanding in month $\mathrm{j}$. Finally, volatility for April in year $t$ is approximated by the standard deviation of monthly stock returns over a period of 5 years (April $\ldots$...Mayt.5). P50 indicates de median of the distribution. T-statistic tests the null hypothesis that the means for UK and Spanish groups are equal. Levene tests the null that the variances for UK and Spanish groups are equal. 
Table III. Test for market myopia

\begin{tabular}{lrrrr}
\hline & \multicolumn{2}{c}{ UK } & \multicolumn{2}{c}{ Spain } \\
\hline$\alpha_{0}$ & Coefficient & p-value & Coefficient & p-value \\
$\alpha_{1}$ & 0.277 & 0.00 & 0.045 & 0.20 \\
$\alpha_{2}$ & 0.449 & 0.03 & 0.714 & 0.01 \\
$\alpha_{3}$ & 5.250 & 0.01 & 4.198 & 0.01 \\
\hline$\square^{2}(4)$ & 0.100 & 0.23 & 0.100 & 0.40 \\
AR(2) & 162.06 & 0.00 & 73.350 & 0.00 \\
Hansen/Sargan test & 0.83 & 0.41 & 0.63 & 0.53 \\
\hline
\end{tabular}

Results of the test for market myopia Panel regression coefficients estimated from equation (1). Estimation using the Generalized Method of Moments (GMM). We compute the two-step estimator. Pvalues are computed using the Windmeijer (2005) finite-sample correction. All the models include time dummies. $\square^{2}(4)$ is the linear restriction test under the following null hypothesis: $H_{0}^{1}: \alpha_{0}=0$ and $\alpha_{1}=\alpha_{2}=\alpha_{3}=1$. The second-order autocorrelations test the null hypothesis of no second-order autocorrelation in the residuals, AR(2) . The Hansen-Sargan test is a test of the over-identifying restrictions under the null hypothesis of instrument validity.

The null hypothesis is: $H_{0}^{1}: \alpha_{0}=0$ and $\alpha_{1}=\alpha_{2}=\alpha_{3}=1$. The alternative hypothesis is that myopic pricing results in the overestimation of near-term earnings and the under-estimation of long-term earnings, as follows: $H_{1}^{1}: \alpha_{2}>1$ and $\alpha_{3}<1$.

$P_{i, t}=\alpha_{0}+\alpha_{1} b_{i, t}+\alpha_{2}\left[\left(1+r_{i}\right)^{-1} E_{t}\left(x_{i, t+1}-r \cdot b_{i, t}\right)\right]+$

$+\alpha_{3}\left[\sum_{s=2}^{T}\left(1+r_{i}\right)^{-s} E_{t}\left(x_{i, t+s}-r_{i} \cdot b_{i, t+s-1}\right)+\left(1+r_{i}\right)^{-T} E_{t}\left(P_{i, t+T}-b_{i, t+T}\right)\right]+d_{t}+\eta_{i}+v_{i, t}$ 
Table IV. Results of the test for market myopia in relation to stock characteristics.

\begin{tabular}{lrrrrrrrr}
\hline & \multicolumn{2}{c}{ BTM } & \multicolumn{2}{c}{ Volatility } & \multicolumn{2}{c}{ Size } & \multicolumn{2}{c}{ Turnover } \\
& Coef & p-val & Coef & p-val & Coef & p-val & Coef & p-val \\
\hline PANEL A: UK & & & & & & & & \\
$\alpha_{0}$ & 0.163 & 0.00 & 0.173 & 0.00 & 0.155 & 0.00 & 0.190 & 0.00 \\
$\alpha_{1}$ & 0.315 & 0.06 & 0.239 & 0.10 & 0.480 & 0.00 & 0.217 & 0.07 \\
$\alpha_{2}$ & 3.903 & 0.05 & 3.055 & 0.08 & 5.772 & 0.00 & 5.421 & 0.00 \\
$\alpha_{2, C}^{*}$ & -3.112 & 0.01 & 2.330 & 0.09 & -1.615 & 0.10 & -1.423 & 0.03 \\
$\alpha_{3}$ & 0.000 & 0.00 & 0.064 & 0.17 & 0.004 & 0.97 & 0.000 & 0.72 \\
$\alpha_{3, C}^{*}$ & -0.042 & 0.40 & -0.065 & 0.16 & -0.004 & 0.97 & -0.001 & 0.79 \\
\hline AR(2) & 0.87 & 0.38 & 0.67 & 0.50 & 0.59 & 0.55 & 0.38 & 0.70 \\
Hansen/Sargan test & 82.95 & 0.51 & 51.22 & 0.24 & 77.16 & 0.38 & 51.22 & 0.24 \\
\hline PANEL B: SP & & & & & & & & \\
$\alpha_{0}$ & 0.086 & 0.08 & 0.100 & 0.00 & 0.054 & 0.07 & 0.041 & 0.15 \\
$\alpha_{1}$ & 0.553 & 0.17 & 0.272 & 0.40 & 0.804 & 0.00 & 0.454 & 0.09 \\
$\alpha_{2}$ & 6.961 & 0.00 & 1.200 & 0.58 & 3.601 & 0.07 & 5.636 & 0.01 \\
$\alpha_{2, C}^{*}$ & -4.190 & 0.01 & 3.778 & 0.05 & -2.894 & 0.12 & -4.628 & 0.03 \\
$\alpha_{3}$ & 0.032 & 0.86 & 0.175 & 0.20 & 0.133 & 0.39 & -0.050 & 0.74 \\
$\alpha_{3, C}^{*}$ & & & & & & & & \\
\hline AR(2) & 0.238 & 0.07 & -0.297 & 0.02 & -0.021 & 0.86 & 0.254 & 0.15 \\
Hansen/Sargan test & 0.98 & 0.33 & 1.24 & 0.22 & 0.67 & 0.50 & 0.25 & 0.81 \\
\hline & 51.85 & 0.33 & 22.78 & 0.53 & 52.22 & 0.31 & 48.10 & 0.47 \\
\hline
\end{tabular}

Panel regression coefficients estimated from equation (2). Estimation using the Generalized Method of Moments (GMM). We compute the two-step estimator. P-values are computed using the Windmeijer (2005) finite-sample correction All the models include time dummies. The second-order autocorrelations test the null hypothesis of no second-order autocorrelation in the residuals, AR(2). The Hansen-Sargan test is a test of the over-identifying restrictions under the null hypothesis of instrument validity. The dummy variable $D_{C}^{*}\left(\mathrm{D}_{\mathrm{BTM}} / \mathrm{D}_{\mathrm{v}} / \mathrm{D}_{\mathrm{S}} / \mathrm{D}_{\mathrm{TU}}\right)$ is equal to 1 if the value of the stock characteristic (Book to market, (BTM)/Volatility (V)/ Size, (S)/ Turnover, (TU)) is above the median and 0 otherwise. The null hypothesis is that stock characteristics have no significant influence on market myopia, $H_{0}^{2}: \alpha_{2, C}^{*}=0$ y $\alpha_{3, C}^{*}=0$ and the alternative hypothesis associates harder-to-value or difficult-to-arbitrage stocks with a higher level of market myopia, $H_{1}^{2}: \alpha_{2, C}^{*}>0$ and $\alpha_{3, C}^{*} \leq 0$.

These hypotheses, applied to individual stock characteristics, read as follows: $H_{1}^{2, B T M}: \alpha_{2, B T M}^{*}<0$ and $\alpha_{3, B T M}^{*} \geq 0$; $H_{1}^{2, V}: \alpha_{2, V}^{*}>0$ and $\alpha_{3, V}^{*} \leq 0 ; H_{1}^{2, S}: \alpha_{2, S}^{*}<0$ and $\alpha_{3, S}^{*} \geq 0 ; H_{1}^{2, T U}: \alpha_{2, T U}^{*}<0$ and $\alpha_{3, T U}^{*} \geq 0$

$$
\begin{aligned}
& P_{i, t}=\alpha_{0}+\alpha_{1} b_{i, t}+\left(\alpha_{2}+\alpha_{2, C}^{*} \cdot D_{i, c}^{*}\right)\left[\left(1+r_{i}\right)^{-1} E_{t}\left(x_{i, t+1}-r_{i} \cdot b_{i, t}\right)\right]+\left(\alpha_{3}+\alpha_{3, C}^{*} \cdot D_{i, C}^{*}\right) \\
& {\left[\sum_{s=2}^{T}\left(1+r_{i}\right)^{-s} E_{t}\left(x_{i, t+s}-r_{i} \cdot b_{i, t+s-1}\right)+\left(1+r_{i}\right)^{-T} E_{t}\left(P_{i, t+T}-b_{i, t+T}\right)\right]+d_{t}+\eta_{i}+v_{i, t}}
\end{aligned}
$$


Table V. Results of the test for market myopia in relation to stock characteristics.

\begin{tabular}{|c|c|c|c|c|c|c|c|c|}
\hline & \multicolumn{2}{|c|}{ Volatility+BTM } & \multicolumn{2}{|c|}{ Volatility+Size } & \multicolumn{2}{|c|}{ Volatility+Turnover } & \multicolumn{2}{|c|}{ Volatility+Other } \\
\hline & Coef & $\mathrm{p}$-val & Coef & $p$-val & Coef & $\mathrm{p}$-val & Coef & $p$-val \\
\hline \multicolumn{9}{|l|}{ PANEL A: UK } \\
\hline$\alpha_{0}$ & 0.165 & 0.00 & 0.154 & 0.00 & 0.168 & 0.00 & 0.157 & 0.10 \\
\hline$\alpha_{1}$ & 0.315 & 0.06 & 0.478 & 0.00 & 0.356 & 0.02 & 0.363 & 0.03 \\
\hline$\alpha_{2}$ & 3.092 & 0.05 & 3.871 & 0.00 & 2.876 & 0.06 & 2.891 & 0.05 \\
\hline$\alpha_{2, C}^{*}$ & 2.570 & 0.01 & 2.191 & 0.09 & 3.138 & 0.14 & 3.132 & 0.01 \\
\hline$\alpha_{3}$ & 0.034 & 0.00 & 0.027 & 0.55 & 0.108 & 0.14 & 0.016 & 0.72 \\
\hline$\alpha_{3, C}^{*}$ & -0.033 & 0.40 & -0.028 & 0.54 & -0.109 & 0.12 & -0.017 & 0.72 \\
\hline $\mathrm{AR}(2)$ & 0.68 & 0.49 & 0.57 & 0.56 & 0.57 & 0.57 & 0.63 & 0.53 \\
\hline Hansen/Sargan test & 96.34 & 0.17 & 51.22 & 0.24 & 32.20 & 0.12 & 73.00 & 0.35 \\
\hline \multicolumn{9}{|l|}{ PANEL B: SP } \\
\hline$\alpha_{0}$ & 0.107 & 0.00 & 0.046 & 0.00 & 0.037 & 0.04 & 0.075 & 0.00 \\
\hline$\alpha_{1}$ & 0.290 & 0.06 & 0.243 & 0.13 & 0.190 & 0.19 & 0.347 & 0.03 \\
\hline$\alpha_{2}$ & 2.305 & 0.05 & 1.167 & 0.03 & 1.738 & 0.04 & 0.833 & 0.16 \\
\hline$\alpha_{2, C}^{*}$ & 6.241 & 0.01 & 6.942 & 0.02 & 5.554 & 0.00 & 3.355 & 0.00 \\
\hline$\alpha_{3}$ & 0.214 & 0.00 & 0.189 & 0.01 & 0.178 & 0.04 & 0.273 & 0.00 \\
\hline$\alpha_{3, C}^{*}$ & -0.504 & 0.40 & -0.349 & 0.00 & -0.657 & 0.00 & -0.311 & 0.00 \\
\hline $\mathrm{AR}(2)$ & 1.55 & 0.13 & 0.79 & 0.43 & 0.76 & 0.45 & 0.88 & 0.38 \\
\hline Hansen/Sargan test & 24.80 & 0.42 & 25.96 & 0.35 & 31.49 & 0.14 & 24.86 & 0.41 \\
\hline
\end{tabular}

Panel regression coefficients estimated from equation (2). Estimation using the Generalized Method of Moments (GMM). We compute the two-step estimator. P-values are computed using the Windmeijer (2005) finite-sample correction All the models include time dummies. The second-order autocorrelations test the null hypothesis of no second-order autocorrelation in the residuals, AR(2). The Hansen-Sargan test is a test of the over-identifying restrictions under the null hypothesis of instrument validity. The dummy variable $\mathrm{D}_{\mathrm{vBT}} / \mathrm{D}_{\mathrm{vs}} / \mathrm{D}_{\mathrm{v} t u}$ is equal to 1 if the value of the stock volatility is above the median and the value of BTM/Size/Turnover is below the median, and 0 otherwise. The dummy variable $\mathrm{D}_{\mathrm{V}+\mathrm{OTHER}}$ is equal to 1 if the volatility value of the asset is above the sample median and either BTM, Size or Turnover is below the median, and 0 otherwise.. The null hypothesis is that stock characteristics have no significant influence on market myopia, $H_{0}^{2}: \alpha_{2, C}^{*}=0$ y $\alpha_{3, C}^{*}=0$ and the alternative hypothesis associates harder-to-value or difficult-to-arbitrage stocks with a higher level of market myopia, $H_{1}^{2}: \alpha_{2, C}^{*}>0$ and $\alpha_{3, C}^{*} \leq 0$.

$$
\begin{aligned}
& P_{i, t}=\alpha_{0}+\alpha_{1} b_{i, t}+\left(\alpha_{2}+\alpha_{2, C}^{*} \cdot D_{i, c}^{*}\right)\left[\left(1+r_{i}\right)^{-1} E_{t}\left(x_{i, t+1}-r_{i} \cdot b_{i, t}\right)\right]+\left(\alpha_{3}+\alpha_{3, C}^{*} \cdot D_{i, C}^{*}\right) \\
& {\left[\sum_{s=2}^{T}\left(1+r_{i}\right)^{-s} E_{t}\left(x_{i, t+s}-r_{i} \cdot b_{i, t+s-1}\right)+\left(1+r_{i}\right)^{-T} E_{t}\left(P_{i, t+T}-b_{i, t+T}\right)\right]+d_{t}+\eta_{i}+v_{i, t}}
\end{aligned}
$$


Table VI. Results of the test for market myopia. Presence of Institutional Investors

\begin{tabular}{|c|c|c|c|c|c|c|c|}
\hline & \multicolumn{2}{|c|}{ Inst. Investors (DII) } & \multicolumn{3}{|c|}{ Banks (Dв) } & \multicolumn{2}{|c|}{ MF\&PP(DM\&P) } \\
\hline & Coef & p-val & Coef & & p-val & Coef & p-val \\
\hline \multicolumn{8}{|l|}{ PANEL A: UK } \\
\hline$\alpha_{0}$ & 0.182 & 0.00 & & 0.177 & 0.00 & 0.274 & 0.00 \\
\hline$\alpha_{1}$ & 0.252 & 0.07 & & 0.220 & 0.13 & 0.540 & 0.01 \\
\hline$\alpha_{2}$ & 7.961 & 0.00 & & 4.595 & 0.01 & 6.806 & 0.00 \\
\hline$\alpha_{2, I}^{*}$ & -2.565 & 0.03 & & 0.278 & 0.74 & -1.627 & 0.09 \\
\hline$\alpha_{3}$ & 0.000 & 0.67 & & 0.000 & 0.01 & 0.123 & 0.18 \\
\hline$\alpha_{3, I}^{*}$ & -0.001 & 0.84 & & -0.002 & 0.75 & 0.018 & 0.81 \\
\hline $\mathrm{AR}(2)$ & 0.49 & 0.62 & & 0.56 & 0.57 & 1.19 & 0.24 \\
\hline Hansen/Sargan test & 52.17 & 0.28 & & 87.59 & 0.24 & 85.02 & 0.45 \\
\hline \multicolumn{8}{|l|}{ PANEL B: SP } \\
\hline$\alpha_{0}$ & 0.023 & 0.56 & & 0.039 & 0.19 & 0.051 & 0.09 \\
\hline$\alpha_{1}$ & 0.740 & 0.01 & & 0.612 & 0.02 & 0.596 & 0.03 \\
\hline$\alpha_{2}$ & 5.100 & 0.14 & & 4.504 & 0.01 & 3.521 & 0.01 \\
\hline$\alpha_{2, I}^{*}$ & -0.984 & 0.74 & & -2.031 & 0.10 & -0.935 & 0.47 \\
\hline$\alpha_{3}$ & 0.022 & 0.92 & & -0.103 & 0.39 & 0.091 & 0.42 \\
\hline$\alpha_{3, I}^{*}$ & 0.062 & 0.76 & & 0.238 & 0.00 & 0.135 & 0.26 \\
\hline $\mathrm{AR}(2)$ & 0.65 & 0.51 & & 0.29 & 0.77 & 0.19 & 0.85 \\
\hline Hansen/Sargan test & 43.68 & 0.48 & & 47.51 & 0.49 & 44.00 & 0.64 \\
\hline
\end{tabular}

Results of the test for market myopia in relation to the presence of institutional investors in the firm ownership structure, both in global terms ( $\left.\mathrm{D}_{\mathrm{II}}\right)$ and by investor type, i.e., banks $\left(\mathrm{D}_{\mathrm{B}}\right)$ and mutual funds/pension funds (MF\&PP) (DM\&P).Panel regression coefficients estimated from equation (3). Estimation using the Generalized Method of Moments (GMM). We compute the two-step estimator. P-values are computed using the Windmeijer (2005) finite-sample correction. The second-order autocorrelations test the null hypothesis of no second-order autocorrelation in the residuals, AR(2). The Hansen-Sargan test is a test of the over-identifying restrictions under the null hypothesis of instrument validity. The dummy variable $D_{I}^{*}$ ( $\mathrm{D}_{\text {III }} / \mathrm{D}_{\mathrm{B}} / \mathrm{D}_{\mathrm{M} \& \mathrm{P}}$ ) is equal to 1 if an institutional investor/bank/mutual fund or pension fund holds a share in the firm ownership and 0 otherwise. The null hypothesis that investor type has no influence on market myopia is $H_{0}^{3}: \alpha_{2, I}^{*}=0$ and $\alpha_{3, I}^{*}=0$. The Bushee (2001) alternative hypothesis that the level of ownership by "transient" institutions is positively related to market myopia is $H_{1}^{3, A}: \alpha_{2, I}^{*}>0$ and $\alpha_{3, I}^{*} \leq 0$. Our alternative hypothesis that the level of the level of ownership by institutional investors is negatively related to market myopia is $H_{1}^{3, B}: \alpha_{2, I}^{*}<0$ and $\alpha_{3, I}^{*} \geq 0$

$P_{i, t}=\alpha_{0}+\alpha_{1} b_{i, t}+\left(\alpha_{2}+\alpha_{2, I}^{*} \cdot D_{i, t}^{*}\right)\left[\left(1+r_{i}\right)^{-1} E_{t}\left(x_{i, t+1}-r_{i} \cdot b_{i, t}\right)\right]+\left(\alpha_{3}+\alpha_{3, I}^{*} \cdot D_{i, I}^{*}\right)$ $\left[\sum_{s=2}^{T}\left(1+r_{i}\right)^{-s} E_{t}\left(x_{i, t+s}-r_{i} \cdot b_{i, t+s-1}\right)+\left(1+r_{i}\right)^{-T} E_{t}\left(P_{i, t+T}-b_{i, t+T}\right)\right]+d_{t}+\eta_{i}+v_{i, t}$ 
Table VII. Results of the test for market myopia. High ownership level by Institutional Investors

\begin{tabular}{|c|c|c|c|c|c|c|}
\hline & \multicolumn{2}{|c|}{ Inst. Investors (D } & \multicolumn{2}{|c|}{ Banks (D } & \multicolumn{2}{|c|}{ MF\&PP(D $\left.D_{M \& P M}\right)$} \\
\hline & Coef & $\mathrm{p}$-val & Coef & p-val & Coef & $\mathrm{p}$-val \\
\hline \multicolumn{7}{|l|}{ PANEL A: UK } \\
\hline$\alpha_{0}$ & 0.188 & 0.00 & 0.176 & 0.00 & 0.235 & 0.00 \\
\hline$\alpha_{1}$ & 0.044 & 0.79 & 0.206 & 0.13 & 0.621 & 0.00 \\
\hline$\alpha_{2}$ & 6.718 & 0.00 & 4.345 & 0.02 & 7.954 & 0.00 \\
\hline$\alpha_{2, I}^{*}$ & -4.697 & 0.02 & 0.294 & 0.75 & -2.425 & 0.02 \\
\hline$\alpha_{3}$ & 0.000 & 0.93 & -0.001 & 0.35 & 0.080 & 0.28 \\
\hline$\alpha_{3, I}^{*}$ & -0.002 & 0.59 & 0.016 & 0.60 & 0.074 & 0.19 \\
\hline $\mathrm{AR}(2)$ & 0.31 & 0.84 & 0.80 & 0.42 & 1.14 & 0.25 \\
\hline Hansen/Sargan test & 59.94 & 0.27 & 83.71 & 0.21 & 83.79 & 0.28 \\
\hline \multicolumn{7}{|l|}{ PANEL B: SP } \\
\hline$\alpha_{0}$ & 0.028 & 0.48 & 0.037 & 0.25 & 0.051 & 0.20 \\
\hline$\alpha_{1}$ & 0.238 & 0.35 & 0.485 & 0.07 & 0.473 & 0.09 \\
\hline$\alpha_{2}$ & 3.949 & 0.02 & 5.281 & 0.00 & 2.534 & 0.05 \\
\hline$\alpha_{2, I}^{*}$ & -2.933 & 0.06 & -4.666 & 0.07 & -0.677 & 0.83 \\
\hline$\alpha_{3}$ & -0.033 & 0.79 & -0.056 & 0.71 & 0.035 & 0.79 \\
\hline$\alpha_{3, I}^{*}$ & 0.320 & 0.06 & 0.306 & 0.17 & 0.268 & 0.16 \\
\hline $\mathrm{AR}(2)$ & -0.23 & 0.82 & 0.29 & 0.77 & -0.08 & 0.94 \\
\hline Hansen/Sargan test & 24.71 & 0.42 & 48.01 & 0.47 & 48.2 & 0.47 \\
\hline
\end{tabular}

Results of the test for market myopia in relation to the presence of an institutional ownership level above the median, both in overall terms (DIIM) and by investor type, i.e., banks(D (BM) $_{\text {) }}$ and mutual funds/pension funds (MF\&PP) (D \&\&PM). Panel regression coefficients estimated from equation (3). Estimation using the Generalized Method of Moments (GMM). We compute the two-step estimator. Pvalues are computed using the Windmeijer (2005) finite-sample correction All the models include time dummies. The second-order autocorrelations test the null hypothesis of no second-order autocorrelation in the residuals. The Hansen-Sargan test is a test of the over-identifying restrictions under the null hypothesis of instrument validity. The dummy variable $D_{I}^{*}$ ( $\mathrm{D}_{\text {IIM }} / \mathrm{D}_{\mathrm{BM}} / \mathrm{D}_{\mathrm{M} \& \mathrm{PM}}$ ) is equal to 1 if the institutional ownership level, i.e., banks and mutual funds/pension funds is above the median and 0 otherwise. The null hypothesis that investor type has no influence on market myopia is $H_{0}^{3}: \alpha_{2, I}^{*}=0$ and $\alpha_{3, I}^{*}=0$. Bushee's (2001) alternative hypothesis that the level of ownership by "transient" institutions is positively related to market myopia is $H_{1}^{3, A}: \alpha_{2, I}^{*}>0$ and $\alpha_{3, I}^{*} \leq 0$. Our alternative hypothesis that the level of the level of ownership by institutional investors is negatively related to market myopia is $H_{1}^{3, B}: \alpha_{2, I}^{*}<0$ and $\alpha_{3, I}^{*} \geq 0$

$$
\begin{aligned}
& P_{i, t}=\alpha_{0}+\alpha_{1} b_{i, t}+\left(\alpha_{2}+\alpha_{2, I}^{*} \cdot D_{i, t}^{*}\right)\left[\left(1+r_{i}\right)^{-1} E_{t}\left(x_{i, t+1}-r_{i} \cdot b_{i, t}\right)\right]+\left(\alpha_{3}+\alpha_{3, I}^{*} \cdot D_{i, I}^{*}\right) \\
& {\left[\sum_{s=2}^{T}\left(1+r_{i}\right)^{-s} E_{t}\left(x_{i, t+s}-r_{i} \cdot b_{i, t+s-1}\right)+\left(1+r_{i}\right)^{-T} E_{t}\left(P_{i, t+T}-b_{i, t+T}\right)\right]+d_{t}+\eta_{i}+v_{i, t}}
\end{aligned}
$$


Table VIII. Test for market myopia for the UK . Stock characteristics and investor type.

\begin{tabular}{|c|c|c|c|c|c|c|c|c|}
\hline \multirow[t]{2}{*}{ UK } & \multicolumn{2}{|c|}{ BTM } & \multicolumn{2}{|c|}{ Volatility } & \multicolumn{2}{|l|}{ Size } & \multicolumn{2}{|c|}{ Turnover } \\
\hline & Coef & p-val & Coef & p-val & Coef & p-val & Coef & p-val \\
\hline \multicolumn{9}{|l|}{ PANEL A: II } \\
\hline$\alpha_{0}$ & 0.163 & 0.00 & 0.165 & 0.00 & 0.157 & 0.00 & 0.175 & 0.00 \\
\hline$\alpha_{1}$ & 0.371 & 0.01 & 0.263 & 0.08 & 0.392 & 0.01 & 0.324 & 0.08 \\
\hline$\alpha_{2}$ & 5.394 & 0.00 & 5.363 & 0.01 & 7.524 & 0.00 & 7.247 & 0.00 \\
\hline$\alpha_{2, I}^{*}$ & -1.460 & 0.18 & -3.561 & 0.09 & -1.117 & 0.42 & -2.921 & 0.08 \\
\hline$\alpha_{2, C}^{*}$ & -3.605 & 0.01 & 1.992 & 0.20 & -3.128 & 0.09 & -1.037 & 0.67 \\
\hline$\alpha_{3}$ & 0.000 & 0.00 & 0.028 & 0.68 & -0.041 & 0.63 & 0.000 & 0.35 \\
\hline$\alpha_{3, I}^{*}$ & -0.003 & 0.39 & 0.028 & 0.66 & 0.041 & 0.63 & -0.058 & 0.59 \\
\hline$\alpha_{3, C}^{*}$ & -0.004 & 0.95 & -0.028 & 0.67 & 0.000 & 0.96 & 0.057 & 0.60 \\
\hline $\mathrm{AR}(2)$ & 0.63 & 0.53 & 0.15 & 0.88 & 0.33 & 0.74 & 0.11 & 0.91 \\
\hline Hansen/Sargan test & 107.87 & 0.59 & 84.40 & 0.56 & 96.82 & 0.34 & 78.90 & 0.39 \\
\hline \multicolumn{9}{|l|}{ PANEL B: Banks } \\
\hline$\alpha_{0}$ & 0.160 & 0.00 & 0.170 & 0.00 & 0.156 & 0.00 & 0.171 & 0.00 \\
\hline$\alpha_{1}$ & 0.390 & 0.01 & 0.342 & 0.01 & 0.452 & 0.00 & 0.374 & 0.02 \\
\hline$\alpha_{2}$ & 4.651 & 0.04 & 3.764 & 0.04 & 5.072 & 0.01 & 4.774 & 0.01 \\
\hline$\alpha_{2, I}^{*}$ & 0.248 & 0.79 & -0.145 & 0.88 & 0.585 & 0.52 & 0.816 & 0.43 \\
\hline$\alpha_{2, C}^{*}$ & -2.902 & 0.02 & 1.649 & 0.10 & -1.349 & 0.08 & -2.048 & 0.09 \\
\hline$\alpha_{3}$ & 0.000 & 0.00 & 0.003 & 0.95 & -0.031 & 0.64 & 0.000 & 0.00 \\
\hline$\alpha_{3, I}^{*}$ & -0.003 & 0.10 & 0.012 & 0.77 & -0.003 & 0.32 & -0.077 & 0.06 \\
\hline$\alpha_{3, C}^{*}$ & -0.031 & 0.53 & -0.004 & 0.94 & 0.031 & 0.64 & 0.077 & 0.06 \\
\hline $\mathrm{AR}(2)$ & 0.84 & 0.40 & 0.71 & 0.47 & 0.73 & 0.465 & 0.38 & 0.71 \\
\hline Hansen/Sargan test & 115.35 & 0.39 & 67.25 & 0.735 & 107.57 & 0.33 & 101.44 & 0.38 \\
\hline \multicolumn{9}{|l|}{ PANEL B: MF\&PP } \\
\hline$\alpha_{0}$ & 0.152 & 0.00 & 0.152 & 0.00 & 0.147 & 0.00 & 0.158 & 0.00 \\
\hline$\alpha_{1}$ & 0.468 & 0.01 & 0.308 & 0.02 & 0.517 & 0.00 & 0.508 & 0.00 \\
\hline$\alpha_{2}$ & 6.932 & 0.00 & 4.433 & 0.02 & 6.886 & 0.00 & 6.570 & 0.00 \\
\hline$\alpha_{2, I}^{*}$ & -2.481 & 0.05 & -3.678 & 0.01 & -2.080 & 0.06 & -1.950 & 0.09 \\
\hline$\alpha_{2, C}^{*}$ & -3.361 & 0.01 & 3.145 & 0.04 & -1.177 & 0.38 & -0.960 & 0.19 \\
\hline$\alpha_{3}$ & -0.047 & 0.31 & -0.158 & 0.18 & -0.068 & 0.36 & -0.026 & 0.56 \\
\hline$\alpha_{3, I}^{*}$ & 0.047 & 0.31 & 0.187 & 0.05 & 0.024 & 0.57 & 0.026 & 0.56 \\
\hline$\alpha_{3, C}^{*}$ & -0.029 & 0.68 & -0.030 & 0.69 & 0.043 & 0.50 & 0.000 & 0.99 \\
\hline $\mathrm{AR}(2)$ & 0.51 & 0.61 & 0.15 & 0.88 & 0.44 & 0.66 & 0.33 & 0.74 \\
\hline Hansen/Sargan test & 94.79 & 0.88 & 69.33 & 0.53 & 113.03 & 0.21 & 113.53 & 0.21 \\
\hline
\end{tabular}

Results of the test for market myopia for the UK in relation to stock characteristics and investor type. Panel regression coefficients estimated from equation (4). Estimation using the Generalized Method of Moments (GMM). We compute the twostep estimator. P-values are computed using the Windmeijer (2005) finite-sample correction All the models include time dummies. The second-order autocorrelations test the null hypothesis of no second-order autocorrelation in the residuals. The Hansen-Sargan test is a test of the over-identifying restrictions under the null hypothesis of instrument validity. The dummy variable $D_{I}^{*}$ (DIIM/ $D_{\text {BM }} / D_{\text {M\&PM }}$ ) is equal to 1 if the Institutional/Bank/MF\&PP ownership level is above the median and 0 otherwise. The dummy variable $D_{C}^{*}\left(\mathrm{D}_{\mathrm{BTM}} / \mathrm{D}_{\mathrm{v}} / \mathrm{D}_{\mathrm{S}} / \mathrm{D}_{\mathrm{TU}}\right)$ is equal to 1 if the value of the stock characteristic (Book to market, (BTM)/Volatility (V)/ Size, (S)/ Turnover, (TU)) is above the median and 0 otherwise. The null hypothesis of no effect associated with investor type or stock characteristics is: $H_{0}^{4}: \alpha_{2, I}^{*}=\alpha_{2, C}^{*}=0$ and $\alpha_{3, I}^{*}=\alpha_{3, C}^{*}=0$ Our alternative hypothesis that asserts the role of stock characteristics and investor type on market myopia is $H_{1}^{4, A}: \alpha_{2, C}^{*}>0$ and $\alpha_{2, I}^{*}<0 ; \quad \alpha_{3, C}^{*} \leq 0$ and $\alpha_{3, I}^{*} \geq 0$. The application of $\alpha_{2, C}^{*}$ and $\alpha_{3, C}^{*}$ to each individual stock characteristic gives: $H_{1}^{4, B T M}: \alpha_{2, B T M}^{*}<0$ and $\alpha_{3, B T M}^{*} \geq 0$; $H_{1}^{4, V}: \alpha_{2, V}^{*}>0$ and $\alpha_{3, V}^{*} \leq 0 ; H_{1}^{4, S}: \alpha_{2, S}^{*}<0$ and $\alpha_{3, S}^{*} \geq 0 ; H_{1}^{4, T U}: \alpha_{2, T U}^{*}<0$ and $\alpha_{3, T U}^{*} \geq 0$

$$
\begin{aligned}
& P_{i, t}=\alpha_{0}+\alpha_{1} b_{i, t}+\left(\alpha_{2}+\alpha_{2, I} \cdot D_{i, I}^{*}+\alpha_{2, C} \cdot D_{i, C}^{*}\right)\left[\left(1+r_{i}\right)^{-1} E_{t}\left(x_{i, t+1}-r_{i} \cdot b_{i, t}\right)\right]+\left(\alpha_{3}+\alpha_{3, I} \cdot D_{i, I}^{*}\right. \\
& \left.+\alpha_{3, C} \cdot D_{i, C}^{*}\right)\left[\sum_{\tau=2}^{T}\left(1+r_{i}\right)^{-\tau} E_{t}\left(x_{i, t+\tau}-r_{i} \cdot b_{i, t+\tau-1}\right)+\left(1+r_{i}\right)^{-T} E_{t}\left(P_{i, t+T}-b_{i, t+T}\right)\right]+d_{t}+\eta_{i}+v_{i, t}
\end{aligned}
$$


Table IX. Test for market myopia for Spain. Stock characteristics and investor type.

\begin{tabular}{|c|c|c|c|c|c|c|c|c|}
\hline \multirow[t]{2}{*}{ SPAIN } & \multicolumn{2}{|c|}{ BTM } & \multicolumn{2}{|c|}{ Volatility } & \multicolumn{2}{|c|}{ Size } & \multicolumn{2}{|c|}{ Turnover } \\
\hline & Coef & p-val & Coef & $\mathrm{p}$-val & Coef & $\mathrm{p}$-val & Coef & $\mathrm{p}$-val \\
\hline \multicolumn{9}{|l|}{ PANEL A: II } \\
\hline$\alpha_{0}$ & 0.068 & 0.12 & 0.068 & 0.08 & 0.049 & 0.18 & 0.047 & 0.21 \\
\hline$\alpha_{1}$ & 0.239 & 0.51 & 0.284 & 0.42 & 0.540 & 0.03 & 0.293 & 0.28 \\
\hline$\alpha_{2}$ & 8.533 & 0.00 & 2.157 & 0.19 & 5.308 & 0.00 & 5.256 & 0.03 \\
\hline$\alpha_{2, I}^{*}$ & -2.956 & 0.04 & -2.897 & 0.08 & -3.104 & 0.06 & -1.349 & 0.48 \\
\hline$\alpha_{2, C}^{*}$ & -4.883 & 0.07 & 5.408 & 0.01 & -3.423 & 0.11 & -2.931 & 0.09 \\
\hline$\alpha_{3}$ & -0.255 & 0.20 & 0.156 & 0.29 & -0.112 & 0.39 & -0.127 & 0.46 \\
\hline$\alpha_{3, I}^{*}$ & 0.367 & 0.02 & 0.144 & 0.13 & 0.275 & 0.05 & 0.273 & 0.09 \\
\hline$\alpha_{3, C}^{*}$ & 0.366 & 0.20 & -0.458 & 0.00 & 0.075 & 0.58 & 0.204 & 0.29 \\
\hline $\mathrm{AR}(2)$ & 0.51 & 0.61 & 0.83 & 0.41 & 0.20 & 0.84 & 0.35 & 0.73 \\
\hline Hansen/Sargan test & 35.22 & 0.32 & 37.92 & 0.47 & 38.32 & 0.20 & 36.66 & 0.26 \\
\hline \multicolumn{9}{|l|}{ PANEL B: Banks } \\
\hline$\alpha_{0}$ & 0.073 & 0.17 & 0.070 & 0.03 & 0.040 & 0.31 & 0.037 & 0.41 \\
\hline$\alpha_{1}$ & 0.281 & 0.46 & 0.281 & 0.43 & 0.419 & 0.14 & 0.268 & 0.35 \\
\hline$\alpha_{2}$ & 10.031 & 0.00 & 3.120 & 0.05 & 6.958 & 0.00 & 7.250 & 0.01 \\
\hline$\alpha_{2, I}^{*}$ & -4.340 & 0.02 & -4.245 & 0.03 & -5.512 & 0.02 & -4.326 & 0.10 \\
\hline$\alpha_{2, C}^{*}$ & -4.504 & 0.10 & 5.834 & 0.01 & -3.501 & 0.07 & -2.526 & 0.26 \\
\hline$\alpha_{3}$ & -0.181 & 0.31 & 0.167 & 0.08 & -0.279 & 0.11 & -0.231 & 0.27 \\
\hline$\alpha_{3, I}^{*}$ & 0.396 & 0.02 & 0.197 & 0.08 & 0.391 & 0.08 & 0.383 & 0.12 \\
\hline$\alpha_{3, C}^{*}$ & 0.290 & 0.29 & -0.503 & 0.00 & 0.169 & 0.26 & 0.227 & 0.25 \\
\hline $\mathrm{AR}(2)$ & 0.70 & 0.48 & 0.91 & 0.36 & 0.43 & 0.69 & 0.11 & 0.91 \\
\hline Hansen/Sargan test & 35.88 & 0.29 & 36.05 & 0.28 & 36.01 & 0.29 & 34.97 & 0.33 \\
\hline \multicolumn{9}{|l|}{ PANEL B: MF\&PP } \\
\hline$\alpha_{0}$ & 0.068 & 0.10 & 0.087 & 0.03 & 0.064 & 0.04 & 0.065 & 0.07 \\
\hline$\alpha_{1}$ & 0.510 & 0.20 & 0.313 & 0.39 & 0.513 & 0.03 & 0.332 & 0.18 \\
\hline$\alpha_{2}$ & 9.213 & 0.00 & 0.109 & 0.96 & 4.728 & 0.01 & 5.661 & 0.01 \\
\hline$\alpha_{2, I}^{*}$ & -2.283 & 0.23 & -0.219 & 0.92 & -1.873 & 0.40 & -0.040 & 0.99 \\
\hline$\alpha_{2, C}^{*}$ & -5.032 & 0.00 & 4.626 & 0.02 & -4.226 & 0.10 & -4.536 & 0.03 \\
\hline$\alpha_{3}$ & -0.217 & 0.37 & 0.174 & 0.15 & -0.100 & 0.52 & -0.115 & 0.57 \\
\hline$\alpha_{3, I}^{*}$ & 0.345 & 0.05 & 0.114 & 0.40 & 0.321 & 0.05 & 0.313 & 0.15 \\
\hline$\alpha_{3, C}^{*}$ & 0.364 & 0.02 & -0.371 & 0.00 & 0.167 & 0.28 & 0.285 & 0.22 \\
\hline $\mathrm{AR}(2)$ & 0.48 & 0.63 & 0.91 & 0.36 & 0.41 & 0.68 & 0.12 & 0.90 \\
\hline Hansen/Sargan test & 37.61 & 0.23 & 29.86 & 0.57 & 34.68 & 0.34 & 35.66 & 0.30 \\
\hline
\end{tabular}

Results of the test for market myopia for SPAIN in relation to stock characteristics and investor type. Panel regression coefficients estimated from equation (4). Estimation using the Generalized Method of Moments (GMM). We compute the twostep estimator. P-values are computed using the Windmeijer (2005) finite-sample correction All the models include time dummies. The second-order autocorrelations test the null hypothesis of no second-order autocorrelation in the residuals. The Hansen-Sargan test is a test of the over-identifying restrictions under the null hypothesis of instrument validity. The dummy variable $D_{I}^{*}$ ( $\mathrm{D}_{\text {IIM }} / \mathrm{D}_{\mathrm{BM}} / \mathrm{D}_{\text {M\&PM }}$ ) is equal to 1 if the Institutional/Bank/MF\&PP ownership level is above the median and 0 otherwise. The dummy variable $D_{C}^{*}\left(\mathrm{D}_{\text {втм }} / \mathrm{D}_{\mathrm{v}} / \mathrm{D}_{\mathrm{S}} / \mathrm{D}_{\mathrm{TU}}\right)$ is equal to 1 if the value of the stock characteristic (Book to market, (BTM)/Volatility (V)/ Size, (S)/ Turnover, (TU)) is above the median and 0 otherwise. The null hypothesis of no effect associated with investor type or stock characteristics is: $H_{0}^{4}: \alpha_{2, I}^{*}=\alpha_{2, C}^{*}=0$ and $\alpha_{3, I}^{*}=\alpha_{3, C}^{*}=0$ Our alternative hypothesis that asserts the role of stock characteristics and investor type on market myopia is $H_{1}^{4, A}: \alpha_{2, C}^{*}>0$ and $\alpha_{2, I}^{*}<0 ; \quad \alpha_{3, C}^{*} \leq 0$ and . $\alpha_{3, I}^{*} \geq 0$ The application of $\alpha_{2, C}^{*}$ and $\alpha_{3, C}^{*}$ to each individual stock characteristic gives: $H_{1}^{4, B T M}: \alpha_{2, B T M}^{*}<0$ and $\alpha_{3, B T M}^{*} \geq 0$; $H_{1}^{4, V}: \alpha_{2, V}^{*}>0$ and $\alpha_{3, V}^{*} \leq 0 ; H_{1}^{4, S}: \alpha_{2, S}^{*}<0$ and $\alpha_{3, S}^{*} \geq 0 ; H_{1}^{4, T U}: \alpha_{2, T U}^{*}<0$ and $\alpha_{3, T U}^{*} \geq 0$

$P_{i, t}=\alpha_{0}+\alpha_{1} b_{i, t}+\left(\alpha_{2}+\alpha_{2, I} \cdot D_{i, I}^{*}+\alpha_{2, C} \cdot D_{i, C}^{*}\right)\left[\left(1+r_{i}\right)^{-1} E_{t}\left(x_{i, t+1}-r_{i} \cdot b_{i, t}\right)\right]+\left(\alpha_{3}+\alpha_{3, I} \cdot D_{i, I}^{*}\right.$
$\left.+\alpha_{3, C} \cdot D_{i, C}^{*}\right)\left[\sum_{\tau=2}^{T}\left(1+r_{i}\right)^{-\tau} E_{t}\left(x_{i, t+\tau}-r_{i} \cdot b_{i, t+\tau-1}\right)+\left(1+r_{i}\right)^{-T} E_{t}\left(P_{i, t+T}-b_{i, t+T}\right)\right]+d_{t}+\eta_{i}+v_{i, t}$ 